\title{
LA TEORÍA DEL CONCURSO APARENTE DE LEYES PENALES Y EL "RESURGIMIENTO" DE LA LEY EN PRINCIPIO DESPLAZADA*
}

\author{
Jean Pierre Matus Acuña**
}

\section{FUNDAMENTOS DEL SISTEMA CONCURSAL}

El problema del concurso de delitos se presenta, cuando, en un mismo proceso, se puede imputar a una persona la realización del supuesto de hecho de varias normas ṕenales.

Como sostuviera Jescheck (1955: 529), si no tuviésemos un sistema penal en el que prima el principio de legalidad, el problema concursal no existiría, ya que la norma penal aplicable siempre sería una sola (la infracción al derecho). Añade Jeschek, que la distinción entre el concurso ideal y el real, esto es, entre la unidad y la pluralidad de hecho, es también consustancial a nuestro sistema penal, pues en él las figuras penales describen acciones $u$ omisiones que, de alguna manera pueden considerarse como unidades.

Sin embargo, esta última apreciación no es del todo exacta, desde dos puntos de vista: primero, porque como veremos a continuación, la idea de que a todo tipo penal corresponde una única acción u omisión, parece responder a una estructuración ideal del tipo penal, que corresponde quizás a supuestos muy simples, pero que por regla general no se encuentran así recogidos en la legislación, al menos en la chilena, donde con frecuencia es el tipo penal el que determina que un conjunto más o menos significativo de acciones se considere un único hecho, para los efectos de su sanción (la llamada unidad jurídica de acción). Y en segundo lugar, porque el régimen concursal que impone a los casos de concurso real (nuestro art. 74) un tratamiento penal diferente al del concurso ideal (nuestro art. 75), es meramente contingente.

En efecto, no sólo lo demuestra así la historia de nuestra propia legislación, sino también la de los arts. 76 y 77 del CP Esp que se tomó de modelo. Así, ya en la reforma del CP Esp de 1870, se limitó drásticamente el efecto de la acumulación material a sólo

\footnotetext{
* Sólo los aspectos fundamentales de este trabajo de investigación fueron tratados en la conferencia en la Escuela de Derecho de la Universidad Católica del Norte (Sede Coquimbo) el dia 5 de Octubre de 2001 dentro.del Seminario "Cuestiones fundamentales de Derecho Penal. Un análisis a la luz de la reforma el Código Penal".

**Mg. y Dr. en Derecho por la U. Autónoma de Barcelona. Prof. Asistente de Derecho Penal en la Universidad de Talca.
} 
30 años de prisión. $Y$ en cuanto a la regla del concurso ideal, su carácter meramente contingente lo demuestra el simple hecho que su aplicación se hizo depender, mediante expresa modificación legal, de si era o no más favorable al reo que la regulación del concurso real (Cfr. Matus (1996:280 nota 692), práctica que alguna jurisprudencia nacional ha asumido, sin necesidad de disposición legal expresa (SC Santiago 1970, en RCP XXIX, 54 y SC Santiago 1971, en RDJ LXVIII, 285, cit. ambas por Etcheberry DPJ IV, 204).

Un somero análisis de derecho comparado nos lleva también a la conclusión del carácter contingente de las disposiciones concursales. Así, mientras el CP español de 1995 regula no sólo el concurso real (art. 73) -para el cual establece un sistema de acumulación material limitada temporalmente a un máximo de treinta años de privación de libertad-e ideal (art. 77) -regido por el principio de absorción agravada, con posibilidad de regresar al sistema de acumulación material, si es más benigno-, sino también, y con detalle, el aparente de leyes (art. $8^{\circ}$ ) y aun el llamado delito continuado (art. 74), para el cual establece un sistema de exasperación, aplicable sólo si resulta más beneficioso que la regla general de acumulación material; el CP Italiano, por su parte, establece en su art. 81 una misma regla de exasperación para los casos de concurso ideal (formale) y delito continuado, limitado a que su aplicación no exceda de la pena que correspondería a los casos de concurso real (concurso de reati), cuya regulación se hace detalladamente en relación a la naturaleza de las penas concurrentes (arts. 72ss), estableciendo un sistema mixto de acumulación jurídica para ciertos casos (arts. 72 y 73: si alguno de los delitos tiene pena de prisión perpetua [ergastolo] o privativa de libertad superior a 24 años perpetuo) y de acumulación material limitada a treinta años de prisión para el resto de los casos (arts. 73, 74 y 78), y además, se establece una regulación concursal especial, en la forma de exasperación menos grave que la del concurso ideal para las casos de error en el golpe (art. 82) y del llamado delito preterintencional (art. 83).

En Alemania, las diferencias entre las distintas formas concursales han ido disminuyendo, al incorporarse al Código Penal un sistema de acumulación jurídica para el tratamiento del concurso real (§53), que le otorga al Juez un amplio margen de determinación, relacionado de alguna manera con la gravedad del conjunto de los hechos enjuiciados ( 54 ); y al mismo tiempo, puesto que el tratamiento del concurso ideal en Alemania sigue la regla de la absorción simple (\$52), y no agravada como sucede en Chile y España, su doctrina ha llegado a afirmar que siendo idénticos los resultados entre apreciar concurso aparente de leyes y concurso ideal, la diferencia entre ambos estaría "reducida a cero" (SCHÖNKE/SCHÖDER/STREE, V. § 52/104).

El CP francés, en cambio, desconoce totalmente la distinción entre concurso real y concurso ideal, y ofrece un único sistema concursal en sus arts. 132-3 y 132-4, basado en la absorción agravada de las penas concurrentes (se permite aplicar el límite 
máximo de la pena más elevada), a menos que sean de distinta naturaleza (corporales y pecuniarias, por ejemplo), caso en el cual opera la acumulación material.

Finalmente, en el sistema federal de los Estados Unidos, los Lineamientos de Sentencia (USSG §1 A4(b)) establecen reglas similares a las de la acumulación jurídica, pero sin tomar en cuenta la unidad o pluralidad de hechos, sino la circunstancia de que una persona haya sido encontrada culpable de múltiples infracciones a la ley en veredictos separados ("Multi-Count Conviction"), sobre la base de que la mera reiteración de ciertas conductas o el aumento del daño que provoca una sola, si bien permite aumentar la pena, no lo haría al punto de poder transformar, por la simple acumulación aritmética, varios pequeños delitos en una cadena perpetua ni lleva a la imposible imposición de varias penas de muerte y cadenas perpetuas.

\section{LA ESTRUCTURA DEL RÉGIMEN CONCURSAL CHILENO}

La regla general de nuestro régimen concursal es la de la acumulación material de penas que se encuentra en el inc. primero del art. 74: "al culpable de dos o más delitos se le impondrán todas las penas correspondientes a las diversas infracciones". A partir de esa regla encontramos una serie de excepciones, que se aplican en el orden de su exposición: a) los casos en que, a pesar de existir realización de varios supuestos típicos o de un mismo tipo varias veces, la ley los considera un único delito, la llamada unidad jurídica de acción, que se sanciona con la pena de un único delito; b) los casos de concurso aparente de leyes, en que un delito desplaza a otro concurrente; c) los casos en que la propia ley establece la solución concursal especial para un delito o grupo de delitos determinados (art. 141 in fine, 150-A, etc.); d) los casos en que un delito es medio necesario para la comisión de otro (concurso ideal impropio, art. 75 inc. $2^{\circ}$ ), en que la ley ordena una absorción (agravada) de la pena de un delito en la del otro; e) los casos de reiteración de delitos (que no se encuentran en una relación de medio a fin) en que la ley ordena una acumulación jurídica de penas (451 CP, 509 CPP 1906, 351 CPP 2000.; y f) los casos en que un mismo hecho constituye dos o más delitos, concurso ideal propio (art. 75 inc. $1^{\circ}$ ). Además, expresamente la ley contempla una contraexcepción que obliga a volver a la regla general del art. 74, en los casos de reiteración de delitos, si su aplicación es más favorable al condenado, misma contraexcepción que jurisprudencialmente se ha reconocido para los casos de concurso ideal y medial (Garrido II, 547). Finalmente, cabe destacar la posibilidad de una aplicación simultánea de varias de las reglas concursales vigentes: así, si un par de hechos se encuentran en concurso medial y se ha cometido otro delito sin relación con ellos, tendremos un concurso real entre el medial y el delito aislado. Lo mismo sucederá, por ejemplo, si se trata de reiteración de dos clases de delitos distinta especie: cada reiteración de delitos de la misma especie, se pena por separado y al final, se reúnen las dos según la regla del art. 74 . 


\section{LOS CASOS EXCLUIDOS DEL RÉGIMEN CONCURSAL COMÚN, POR EXISTIR UN CONCURSO APARENTE DE LEYES}

\subsection{El fundamento del concurso aparente de leyes}

La distinción entre las figuras concursales comunes y el concurso aparente de leyes se encuentra dada por la presencia o no de los requisitos de aplicabilidad de alguno de sus distintos principios de solución, esto es, de una relación de especialidad, consunción subsidiariedad, o alternatividad, aunque domina en Chile la idea de que bastarían los dos primeros principios enunciados para comprender todos los casos posibles del concurso aparente de leyes (Cf. Matus (2000:295)). Para justificar esta preferencia, y con ello, sobre todo, la distinción entre concurso de leyes y concurso ideal, se recurre habitualmente a los argumentos de la unidad del bien jurídico protegido (Cury II, 284) y de la posibilidad de una violación al principio non bis in idem (Etcheberry II, 125).

Sin embargo, el criterio de la unidad del bien jurídico sólo podría llegar a tener un rol limitado en esta materia y no siempre carente de discusión: primero, porque no es aplicable en muchos casos reconocidos de concurso de leyes, como en la relación existente entre los llamados delitos complejos y los simples de que se compondrían, ni tampoco en otros de concurso ideal con unidad de bien jurídico, tal como sucedería con el llamado concurso ideal homogéneo; y en segundo término, porque este criterio nos remite a otra serie de discusiones posteriores que reducen su valor práctico como delimitador de especies concursales, discusiones que abarcan desde el concepto mismo de lo que ha de entenderse por bien jurídico protegido hasta el particular bien jurídico que protegerían las figuras legales en juego.

Un análisis detallado de los casos de concurso aparente de leyes nos lleva a la conclusión de que para diferenciarlos de las figuras concursales comunes, y justificar con ello su aplicación preferente, se debe recurrir a dos criterios de distinta naturaleza: por una parte, el principio non bis in idem, y por otra, el principio de insignificancia.

El principio non bis in idem justificará la preferencia de los principios de especialidad, subsidiariedad, y alternatividad, cuando en la concurrencia de dos o más normas, la estimación conjunta de ambas suponga una relación lógica entre ellas que lleve necesariamente a tomar en cuenta dos o más veces un mismo elemento del hecho jurídicopenalmente relevante y común a todas las normas concurrentes (CID (1994:53)).

En cambio, en los casos de consunción, regidos por el principio de insignificancia, no tienen lugar las relaciones lógicas existentes entre los preceptos en juego, sino que existen ciertas relaciones empíricas entre hechos susceptibles de ser calificados por dos o más preceptos, en el que la realización de uno ellos se presenta 
como insignificante frente a la del otro, cuya intensidad criminal lo absorbe. En estos casos, la no aplicación de la pena correspondiente al delito de menor intensidad se justifica, porque al ser hecho copenado insignificante en relación al principal, el castigo por éste parece suficiente para señalar tanto al autor como al resto de la población, la reprobación jurídica de su conducta, pareciendo desproporcionado castigar, además, por los hechos acompañantes que, en la consideración del caso concreto, no tienen una significación autónoma.

\subsection{Los principios de solución del concurso aparente de leyes. Casos que comprenden}

\subsubsection{Casos de especialidad}

Existe una relación de especialidad entre dos preceptos penales. En su sentido lógico-formal, cuando en la descripción del supuesto de hecho de uno de ellos, el especial, se contienen todos los elementos del otro, el general, más uno o varios otros especializantes, como el caso del parricidio frente al homicidio (especialidad por extensión o adición); o cuando la descripción de uno o varios elementos del supuesto de hecho de la ley especial suponen conceptual y necesariamente la de todos los de la ley general, porque es un parte de un todo o una especie de un género conceptual, (especialidad por comprensión o especificación), como el caso de la relación entre la estafa y la falsificación de documentos privados (SCS 6.10.1953, en RDJ L, 192). Dicho en términos más comprensivos, especialidad es la relación que existe entre dos supuestos de hecho legales, cuando todos los casos concretos que se subsumen en el supuesto de hecho legal de una norma, la especial, se subsumen también dentro del de otra norma, la general, la que es aplicable al menos a un caso concreto adicional no subsumible dentro del supuesto de hecho de la primera.

\subsubsection{Casos de subsidiariedad}

Este principio es rechazado por la doctrina chilena mayoritaria, considerando que se refiere a situaciones abarcables por el principio de especialidad o el de consunción, o a simples delimitaciones del alcance de ciertas normas, sin contenido material (por todos, Etcheberry II, 127). Sin embargo, aunque es cierto que las reglas de los arts. 8, 16 y 17 pueden verse de esa última manera, no lo es menos que existen una serie de casos no abarcables por esas reglas ni por las de especialidad o consunción, que van más allá de consideraciones "puramente utilitarias" de "política criminal" (Cury II, 284). Son los casos en que en la relación entre dos preceptos legales por lo menos un caso concreto que es subsumible en uno de dichos preceptos lo es también en el otro, y por lo menos un caso concreto que es subsumible en el primero no lo es en el segundo, y viceversa, siempre que ambos preceptos tengan en común al menos una 
misma propiedad jurídico-penalmente relevante. Conforme a este concepto, podemos afirmar existe una relación de subisdiariedad tácita, básicamente en los siguientes casos: a) Entre las diversas especies de un mismo delito básico, por ejemplo, la relación entre las lesiones graves-gravísimas y las mutilaciones (Politoff/Bustos/Grisolía, 280) y b) En ciertos casos de delitos progresivos, donde el paso de una infracción penal a otra supone la mantención de una misma propiedad subjetiva u objetiva del hecho, como en el caso del paso del delito de peligro al de lesión lo constituye la puesta en peligro del objeto de protección penal, como sucede con las distintas modalidades del manejo en estado de ebriedad del art. 121 de la Ley de Alcoholes. En estos casos, y siguiendo los criterios propuestos por el legislador al regular la concurrencia de circunstancias atenuantes y agravantes, donde en general, las primeras tienen un mayor valor que las segundas, y éstas solo permiten aumentar en grado la pena cuando concurren dos o más y ninguna atenuante, podemos ofrecer las siguientes reglas de solución: $1^{\circ}$. Si concurren dos o más figuras calificadas de una misma básica, como en el caso de las relaciones entre lesiones graves-gravísimas y mutilaciones, ha de ser preferente y principal la que contenga la calificación más grave, en el caso propuesto, la del delito del art. $397 \mathrm{~N}^{\circ} 1$; y $2^{\circ} \mathrm{Si}$ concurren una figura privilegiada con una o más calificadas, como sería el caso del infanticidio y el homicidio calificado, se considerará preferente y principal la figura más benigna, en este caso, el infanticidio, tomando en cuenta la circunstancia calificante que concurra como agravante para los efectos de aplicar la regla del art. 68 .

\subsubsection{Casos de alternatividad}

Este criterio es reconocido en nuestra doctrina sólo por Labatut/Zenteno I, 174 . aunque con un concepto distinto al que se dará aquí. En sus orígenes, Binding concibió la alternatividad como un recurso para subsanar errores groseros en la legislación alemana, que se producían por dos razones: a) porque "exactamente el mismo supuesto de hecho es penado por distintas leyes", y b) porque los tipos se configuraban como "dos círculos que se cortan el uno al otro" (Binding, Karl: Handbuch des Strafrechts Bd. I, Leipzig 1885, p. 349). Con las sucesivas reformas sufridas por el CP Alemán, se llegó a la conclusión que este principio carecía de operatividad general, porque sus casos estaban incluidos en los otros, o porque, corregida la legislación, no era ya posible fundar una teoría en un "error legislativo" (Geerds, 1961:226s). Desde esta perspectiva, es posible afirmar, en general, que este principio carecería de operatividad. Sin embargo, en nuestra legislación subsisten muchos de los "errores legislativos" que utilizaba como ejemplo Binding, y respecto de los cuales parece prudente mantener el recurso a este criterio. Los casos más frecuentes son aquellos en que las circunstancias pensadas como agravantes terminan siendo un privilegio, como sucede entre nosotros con la relación entre el art. 403 bis (envio de cartas explosivas) y las figuras de homicidio: el riesgo indiscriminado que produce el envio de una carta explosiva justifica 
que se sancione aún cuando no se afecte "la vida o la integridad corporal de las personas", y que, respecto a las lesiones que se produzcan, la pena prevista en el art. 403 bis (presidio mayor en su grado mínimo), las absorba. Sin embargo, es dudoso que el legislador pretendiese, como aparece de la literalidad del texto legal, que si se envíe una carta explosiva, se ponga en riesgo a una serie indeterminada de personas $y$, en definitiva, se afecte la vida de una o varias personas, ese hecho tenga una pena inferior aún a la del homicidio simple y muy inferior a la del homicidio calificado, cuando no parece difícil pensar que aquí estamos ante un caso de premeditación o alevosía. Por eso, si el hecho es perfectamente encuadrable en dos disposiciones legales, es perfectamente posible dar lugar al principio de alternatividad para su tratamiento penal, prefiriendo, en el caso concreto, la ley más severa (una situación similar ocurre con la "agravación" del art. 317, respecto de los delitos contra la salud pública: en muchas casos resulta inferior a la pena que correspondería por el homicidio calificado o el parricidio correspondiente). $Y$ el otro caso que menciona Binding, y que se reproduce también en nuestra legislación, es el de las figuras en principio especiales y calificadas, pero que resultān por errores del legislador no precisamente más graves que las figuras genéricas a que se refieren, lo que ocurría en la Alemania de Binding con los atentados cometidos contra los Príncipes de la Federación, y sucede en Chile, por ejemplo, con la relación entre el secuestro político del art. $5^{\circ}$.b) LSE y el art. 142 CP: jla figura menos grave de sustracción de menores tiene mayor pena que la sustracción de un menor con propósitos políticos!. En estos casos, puede volverse hacia la figura general y, aplicando el principio de alternatividad, imponer la pena más grave que corresponda al caso concreto.

\subsubsection{El principio de consunción}

En los casos de consunción no estamos ante relaciones lógicas, sino ante valoraciones del sentido de cada una de las normas en juego, según su forma de realización concreta en los hechos enjuiciados, y por tanto, se incluyen en él todos aquéllos supuestos en que, no siendo apreciable una relación de especialidad, subsidiariedad o alternatividad, debe rechazarse no obstante el tratamiento concursal común porque uno de los preceptos concurrentes regula un hecho que sólo puede considerarse como accesorio o meramente acompañante, en sentido amplio, del que regula el precepto principal y desplazante: los llamados actos anteriores, propiamente acompañantes y posteriores copenados. Como señala Etcheberry II, 125, esto es lo que reconoce expresamente el legislador respecto del delito de daños, al disponer el art. 488 que sólo se castigará cuando el hecho no pueda considerarse constitutivo de otro delito que merezca mayor pena. Naturalmente, al faltar el fundamento lógico de la relación que se trata, y depender ésta de factores empíricos, resultará difícil decidir en cada caso la regla a aplicar, presentándose un serie de supuestos limítrofes que no pueden ser determinados a priori. 
A esta dificultad hay que sumar el hecho de que tampoco es posible establecer a priori cuál de los preceptos concurrentes va a ser preferente, ya que esto lo determina sólo la intensidad relativa que tenga cada uno de ellos en el caso concreto, debiéndose descartar la tesis que sostiene siempre será preferente la ley más grave (un caso sería el de la mujer que se intenta suicidar estando embarazada, y pierde a la criatura pero sobrevive: no debe castigarse como si hubiese cometido un aborto: el hecho principal impune-suicidio- absorbe al meramente acompañante-aborto-, consunción inversa).

Sin embargo, el desarrollo de la teoría del concurso aparente de leyes permite, de todos modos, ofrecer una serie de grupos de casos en que se encuentra más o menos consolidada la opinión según la cual el precepto que regula un hecho anterior, posterior o simultáneo a otro no puede ser aplicado conjuntamente con aquél en que es subsumible éste.

A continuación se ofrece una lista de actos anteriores, acompañantes y posteriores que no es, en todo caso, taxativa ni definitiva, porque la consunción, tal como aquí se entiende, no permite postular una lista de esas características, ya que la cuestión queda entregada en general a la valoración del caso concreto, sirviendo los casos propuestos como guía para decidir si aplicar o no dicha disposición legal, pero en ningún caso como un mandato de obligatorio cumplimiento, ya que lo decisivo en todos estos casos es determinar la verdadera intensidad criminal de los hechos en juego, y en particular, el juicio sobre la insignificancia, a efectos penales, de uno de ellos en atención a su relación con el o los restantes. Los casos son los siguientes:

\section{a) Actos anteriores copenados}

Se comprenden entre ellos:

1. Los que consisten en la realización de una forma de participación en el delito anterior a su ejecución, respecto de ésta, como el paso de la inducción a la coautoría o de la complicidad simple a la necesaria o de todas las mencionadas a la autoría material.

2. Los que consisten en la realización de tentativas fallidas de comisión de un mismo delito antes de su consumación y en relación a ésta, siempre que se mantenga una misma voluntad criminal y no varíe el objeto material del delito tentado.

3. Los que consisten en actos preparatorios especialmente punibles en relación a la tentativa y la consumación del delito preparado, como p. ej., sucedería entre las disposiciones del art. 445 (porte de instrumentos conocidamente destinados al robo) y las de robo con fuerza de los arts. 440 y 442 . 
4. Las existentes entre los delitos de peligro, concreto o abstracto, y los delitos de lesión a los bienes jurídicos puestos en peligro, como sucede en las amenazas seguidas del mal amenazado y en el incendio en lugar habitado seguido de incendio con resultado de muerte, siempre que no exista una disposición legal en contrario (como la del art. 406) o el peligro efectivamente producido sea de carácter general y se extienda más allá del bien jurídico dañado en concreto.

5. Las existentes entre los llamados delitos progresivos - de tránsito en la nomenclatura alemana- y el delito a que conducen (las formas más graves de consumación absorben a las menos graves), p. ej., el paso de lesiones menos agraves a graves o de éstas a un parricidio u homicidio doloso.

\section{b) Actos propiamente acompañantes típicos o copenados}

Se comprenden entre ellos:

1. Los consistentes en la realización de diversas formas de participación en el delito simultáneas a la ejecución material del mismo, en relación a la autoría. Así sucede con el paso sin solución de continuidad de acciones de complicidad simple a la complicidad necesaria y aún a la autoría material.

2. Los consistentes en hechos de escaso valor criminal que acompañan regularmente la comisión de ciertos delitos, como las injurias de hecho y las lesiones leves acompañantes de ciertos delitos de homicidio y lesiones; los daños y el allanamiento de morada que acompañan típicamente al robo con fuerza de los arts. 340 y 342 , etc.

\section{c) Actos posteriores copenados}

Se comprenden entre ellos:

1.- Los que consisten en el aprovechamiento o destrucción de los efectos del delito en cuya comisión se ha tomado parte, como sucede típicamente en los casos de delitos contra la propiedad.

2.- Los que consisten en el agotamiento de la intención puesta en el delito preferente, como el uso del documento falsificado por parte de quien lo falsifica, arts. 193, 194 y 196.

3. Los que consisten en actos de autoencubrimiento, como el uso ilegítimo de bienes provenientes del tráfico ilícito de estupefacientes por parte de quien realiza las operaciones de tráfico de las cuales provienen esos bienes. 


\title{
4. Los (efectos residuales) y el (resurgimiento) de la ley en principio desplazada
}

\subsection{Tratamiento del problema en la dogmática alemana}

\author{
4.1.1. Los (efectos residuales) de la ley en principio desplazada (o su aplicación en \\ conjunto con la preferente)
}

Hasta que no comenzó a tomar fuerza en Alemania la interpretación del $\S 73$ StGB 1871 que dió paulatina entrada al llamado principio de combinación para el tratamiento penal del concurso ideal ${ }^{1}$, el del concurso (aparente) de leyes no fue objeto

'El principio de combinación de las penas consiste en la aplicación de ciertos efectos penales de la ley desplazada más benigna, básicamente, de sus penas accesorias y principiales no contempladas en la ley preferente más severa, y de su marco penal mínimo, como mínimo imponible en el caso concreto, aunque la ley preferente más severa contemplase uno inferior. El antecedente de este principio fue la admisión por parte de la doctrinà y jurisprudencia alemanas de la aplicación de ciertas consecuencias accesorias no penales (compensaciones, medidas de seguridad y policía) contempladas sólo en la ley más benigna, y la posibilidad de fundamentar una reincidencia, a partir de la declaración de culpabilidad v.gr. los delitos de que se trate [asi ya MERKEL (1877:230); v.gr. Cfr. BAUMGARTEN (1909:95)]. Muy pronto comenzaron a plantearse las consecuencias relevantes del principio de combinación, como la imposibilidad de imponer una pena inferior al mínimo penal de la ley desplazada o la admisión de sus penas accesorias, pero eran prácticamente rechazadas del todo, según puede verse en LISZT (1884:224) y WACHENFELD (1893:82s). Sólo con KOHLER (1900:146ss) se comienza a estimar seriamente la violación de la ley desplazada en la determinación de la pena, para evitar que el concurso le resulte beneficioso al acusado. Después, THOMSEN (1906:109) afirmaria que "el Juez no está autorizado" para imponer, en base al marco penal más grave, una pena que fuese más benigna que el mínimo establecido por la ley desplazada. M. MAYER (1915:510) afirmaría posteriormente que la aplicación del principio de exclusividad "no debe llevar al punto" de admitir la aplicación de una pena de menor gravedad que el mínimo penal de la ley desplazada, "pues entonces el concurso ideal tendría un significado privilegiante". Con esta afirmación, se pierde definitivamente el significado original del establecimiento del $\S 73$ que, en comparación al § 74, no era otro que, efectivamente, privilegiar [cfr. BAUMGARTEN (1909:89), y en contra de este privilegio MERKEL (1889:270)]. por medio del principio de absorción, a quien había cometido una pluralidad de delitos en uno y no en varios actos. En el periodo entreguerras, aunque algunos autores, como LISZT/SCHMIDT (1932:360) y GERLAND (1932:217), todavia mantienen la interpretación tradicional del $\$ 73$ en el sentido de la "estricta exclusividad", se va haciendo cada vez más lugar la idea de que la comisión de varios delitos en un mismo hecho no ha de beneficiar al autor y que las consecuencias penales desfavorables contenidas en la ley más benigna debían también aplicársele, aunque no las contuviese la ley más severa. Así, Frank (1931:§73/V), aunque declaraba "inadmisible" "toda combinación de leyes", refiriéndose con ello a la aplicación de las penas accesorias de la ley más benigna, admitía no obstante que "el Juez no tiene permitido bajar del minimo de la ley más benigna", "pues de la coicurrencia de un delito con otro no puede resultar nunca un privilegio" $(\S 73 / \mathrm{IV}, 1)$. Por su parte, HIPPEL (1930 II:522s) y HIRSCHBERG (1934:36) afirmaban la necesidad de estimar la ley desplazada en la determinación de la pena y la imposibilidad de rebajar el mínimo penal establecido por aquélla. Sin embargo, la aceptación general y completa del principio de combinación sólo tuvo lugar a raiz de una serie de decisiones de los tribunales durante el régimen nacionalsocialista, de las cuales la más importante de todas sin duda fue la del Pleno del RG de 22 de marzo de 1939, donde considerando que "el autor no puede alcanzar un beneficio cuando mediante su acto no sólo ha violado una, sino varias leyes penales", como seria el caso en que contemplando en abstracto una ley una pena más grave que otra, atendidas las concretas circunstancias del caso (p. ej., si se trata de un "caso normal" y no de un "caso especiamente grave"), en concreto la pena aplicable resulte inferior al mínimo penal establecido por la ley en abstracto más grave, se afirmó lo siguiente: "1. Si un mismo hecho viola varias leyes penales, entonces debe respetarse el mínimo del marco penal y la clase de pena de la la ley más benigna, cuando según la ley más grave pudiera admitirse una pena o clase de pena menor; 2 . En unidad de hecho [concurso ideal] deben aplicarse las penas accesorias prescriptivamente establecidas en la ley más benigna, y pueden aplicarse aquéllas que quedan entregadas al criterio del juez". Según HARTUNG (1939:1485), esta nueva interpretación 
de especial atención por parte de la doctrina ${ }^{2}$. La razón para ello es sencilla: en tanto se mantuvo la idea que el $\S 73$ regulaba el concurso ideal mediante un sistema de absorción que implicaba la "estricta exclusividad" de la ley que contuviera "la pena más grave ${ }^{\prime \prime}$, no podía verse una diferencia esencial entre el tratamiento penal del concurso ideal, y el de la mayor parte de los supuestos de concurso (aparente) de leyes. Ello por cuanto, salvo en los casos en que concurría una figura especial privilegiada, el tratamiento penal que se predicaba del concurso (aparente) de leyes era exactamente el mismo establecido por el $\S 73$ para el concurso ideal: en los casos de concurrir una figura calificada, se aplicaría ésta, por su propia naturaleza más gravemente sancionada; y con independencia de las distintas concepciones que se tenían sobre la subsidiariedad y la consunción, resultaba siempre que la lex principal y la lex consumens amenazaban con una pena "más grave" que la establecida por la disposición desplazada en cada caso; mientras que la aplicación de la "ley más

$\S 73$, importaría la creación de un "marco penal especial, que tenga en cuenta el más alto mínimo penal y el más grave máximo penal previstos en cualquiera de las leyes, junto a las penas y consecuencias accesorias de ambas". Sin embargo, este extremo fue rechazado por SCHWARZ (1939:673), quien limitaba la nueva interpretación del RG a la aceptación del principio de combinación, en el sentido de aplicarlo si ello se desprendía de la comparación en concreto de las penas resultantes y no en relación al abstracto marco penal previsto en los pará grafos respectivos, pero sin llegar a ver en ella ese "marco penal especial". Por su parte, BOCKELMANN (1941:293) planteó también la necesidad de extender los efectos de la ley en abstraco más benigna, por una parte, mediante la comparación de las penas concretas a aplicar siguiendo una u otra ley, de manera que en concreto resulte también que el máximo de la pena más severa sea superior al de la más benigna; y por otra, mediante la aplicación no sólo de las penas accesorias contempladas en la ley más benigna, pero no establecidas en la más severa, sino también del resto de las penas principales contempladas en la ley más benigna y que no lo estuvieran en la más severa. No es de extrañar que bajo este influjo, pronto comenzase a postularse directamente el tránsito de la aplicación del principio de combinación al de exasperación, como paso previo a la total introducción de una pena única [PETERS (1944:221)]. Sin embargo, una vez terminado el periodo nacionalsocialista, aparecen nuevamente autores que, como MEZGER (1949;478) y H. MAYER (1953:412) mantienen el criterio tradicional de la "estricta exclusividad" para el tratamiento del concurso ideal, a pesar de "todo lo inadecuado que se quiera sean sus resultados" -MEZGER-, y admiten solamente la combinación de los efectos no penales de la ley más benigna 0 , a lo más, la influencia de la situación concursal en la determinación concreta de la pena -MAYER, H.- (Oo. con el propio MEZGER (1941:922s), quien durante el régimen nacionalsocialista se habia preocupado de otorgar fundamentos materiales al principio de combinación, afirmando que ni la literalidad del § 73 ni la historia del tratamiento penal del concurso ideal se oponian decisivamente al mismo, sino al contrario, puesto que desde antiguo se postulaba para el concurso ideal incluso la posibilidad de exasperar la pena del delito más grave. La unica traba que entonces veia MEZGER (1941:923) para aplicar el principio de combinación era la posible incompatibilidad de las penas que pudieran combinarse, aunque no le otorga al punto demasiada importancia).

2

Cfr. v.gr. BAUMGARTEN (1909:95). No obstante, desde una perspectiva totalmente diferente, anteriormente contrapuso HEINEMANN (1893:108s) el tratamiento penal del concurso (aparente) de leyes al del § 73, afirmando la posibilidad, negada para los supuestos de concurso ideal, de aplicar en caso de no serlo uno de los principios clásicos de solución, el pro reo o in dubio mitius.

${ }^{3}$ FRANK (1931: $\$ 73 /$ VII,3), HIPPEL (1930:527), GERLAND (1932:216), HIRSCHBERG (1934:36).

${ }^{4}$ Esto parece claro en los casos de subsidiariedad expresa que se citan y, reflexivamente, también en los de la tácita, pues sólo de esa manera puede entenderse que la ley principal represente un "estadio más grave de ataque a un mismo bien jurídico". Lo mismo sucede en los casos de consunción, cuyo primitivo nombre, "consunción de una amenaza penal en otra", es más que significativo al respecto. 
gravemente penada" era expresamente afirmada por quienes aceptaban de una u otra manera el principio de alternatividad en el sentido que BINDING le atribuía ${ }^{5}$.

De allí que, una vez admitida la combinación de los efectos penales de los delitos concurrentes en los supuestos de concurso ideal, una parte de la doctrina creyó ver la diferencia entre esta figura concursal y el concurso (aparente) de leyes en que el tratamiento penal de este último no estaría regido por el dicho principio de combinación, sino por el tradicional de la "exclusividad estricta" de la ley preferente, con el consecuente desplazamiento absoluto de la ley preterida ${ }^{6}$. Si bien se mira, esta sería la situación actualmente aplicable al derecho chileno: el concurso ideal se encuentra regido por la regla de la absorción agravada del art. $75 \mathrm{CP}$, mientras el concurso aparente de leyes operaría el simple desplazamiento de la ley preferida.

Sin embargo, en Alemania dicha diferencia no pudo sostenerse unánimente por mucho tiempo, pues después que la jurisprudencia alemana aceptase extender la aplicación del principio de combinación a supuestos de concurso (aparente) de leyes ${ }^{7}$, también comenzó a hacerlo parte de la doctrina, con el argumento de que, aunque no se estimase concurso ideal, "el autor no puede obtener ninguna ventaja del hecho de haber violado con su acción no sólo una, sino varias leyes penales ${ }^{1{ }^{8}}$. La aplicación del principio de combinación al tratamiento penal del concurso (aparente) de leyes se reflejaría, según SCHNEIDER (1953:660) en tres aspectos: 1) limitación del marco penal de la ley desplazante por el mínimo de la ley desplazada; 2) aplicación de las penas principales y accesorias contenidas sólo en la ley desplazada; y 3) estimación de la violación de la ley desplazada en la determinación definitiva de la pena. Por su parte, BOCKELMANN (1953:235) admite incluso la posibilidad de aplicar el principio de combinación en supuestos de delitos privilegiados, cuando "las relaciones de las amenazas penales no se correspondan con las de sus presupuestos penales", esto es, cuando exista un "error" que conduzca a priviligiar algo que no lo debiera ser. En estos

\footnotetext{
${ }^{5}$ En cambio, tal necesidad no existía entre quienes admitían el concepto de LISZT, pero como en tales situaciones tampoco había propiamente una concurrencia, resulta irrelevante para estos efectos. ${ }^{6} \mathrm{M}$ MEZGER (1949:478), BERG (1953:28) y H. MAYER (1953:412), cfr. nota 121 in fine.

Al respecto, cfr. NIESE (1953:175) y DÜNNEBIER (1954:272s).

${ }^{8}$ SCHNEIDER (1953:660) y BOCKELMANN (1953:234s), anticipados eso si en una tímida medida por NAGLER (1944:V. §73/p. 551), SCHÖNKE (1951: $73 /$ VII, 5) y H. MAYER (1953:413), quienes proponían estimar la ley desplazada en la determinación de la pena, aunque limitado el primero a los supuestos que estimaba en consunción, y el último a los por él denominados actos anteriores y posteriores copenados. Todavia más atrás en el tiempo, pueden encontrarss antecedentes de una tímida combinación ya en la obra de BINDING (1885:365. 367). y también a propósito del principio de consunción, donde proponia estimar en la determinación de la pena de los de los delitos de homicidio y lesiones las injurias por vías de hecho consumidas en ellos y, en los casos de delitos calificados por el resultado en que se hubiese causado la muerte o lesiones de la víctima, aplicar analógicamente el mínimo penal de los delitos de homicidio y lesiones en caso que se aplicase la pena del delito calificado por el resultado por ser superior a la de aquéllos.
} 
casos, afirma el autor "debe permitirse corregir el error, mediante la aplicación de la amenaza penal de la norma general" $1{ }^{9}$.

Con este giro, pasó a ser dominante en la doctrina, en el período posterior a 1954 la aplicación al concurso (aparente) de leyes del llamado principio de combinación ${ }^{10}$, básicamente porque también lo era la idea de que en el concurso (aparente) de leyes se lesionaban efectivamente varias leyes penales, pero sólo una resultaba aplicable. Sólo aisladas voces clamaban por la vuelta a la tradicional exclusividad de la ley desplazante ${ }^{11}$.

Entre estas últimas, la más destacada es la de GEERDS (1961:231s), quien puso de manifiesto la imposibilidad de aplicar las consecuencias del principio de combinación a los supuestos de concurso (aparente) de leyes en que resultaba preferente la ley más levemente penada, pues en tal caso el efecto privilegiante de ésta desaparecería por completo, imposibilidad de la cual deduce la absoluta exclusión de la ley desplazada como tratamiento penal para todos los supuestos de concurso (aparente) de leyes.

\footnotetext{
9 Sin embargo, esta extensión no parece aceptable, pues significaría prácticamente convertir las figuras privilegiadas en una mera declaración de intenciones sin valor alguno, pues dado que siempre que concurre una figura privilegiada lo hace también la general, si se aplican los efectos penales de esta última nunca lo serian en los hechos los de la primera, todo el privilegio desaparecería con la incorporación de los efectos penales de la ley general. La justificación ofrecida por BOCKELMANN, esto es, el "error legislativo" que conduciría a establecer una figura privilegiada donde no corresponderia, no puede ser aceptada en modo alguno, pues si el privilegio constituye o no un "error" del legislador sólo depende de valoraciones ajenas al mismo, y por tanto no parece fácilmente demostrable, aparte de que si él quisiera remediar ese "error", siempre podría hacerlo soberanamente. Pero no es ésta la crítica fundamental contra el razonamiento de BOCKELMANN, sino la que se deriva de su propuesta de actuación contra legem y, además, contra el reo. En efecto, aún cuando se llegase a aceptar que el legislador se ha equivocado al establecer un privilegio, no es ésta una razón suficiente para lesionar el principio de legalidad, generalmente de rango constitucional, establecido, entre otras razones, precisamente para proteger a los ciudadanos contra la libre determinación de la pena y sus presupuestos por parte de la judicatura.

10

Después que DÜNNEBIER (1954:273s) introdujese este principio en el tratamiento penal de los casos de subsidiariedad expresa, más resistentes a ello por su propia literalidad, lo admitieron plenamente NIESE (1954:157), SCHÖNKE/SCHRÖDER (1954:V. §73/VII,5), JAGUSCH (1957:V. §73/C); KOCH (1960:1), SCHMITT (1963:53); SCHRÖDER (1965:729), HRUSCHKA (1967:47); BAUMANN (1968:630), ZIPF (1969:139) y WELZEL (1969:234). En un sentido más limitado KOHLRAUSCH/LANGE (1961: ₹. § 73/III,4) admiten para todos los supuestos de concurso (aparente) de leyes el "efecto residual" del límite mínimo del marco penal de la ley "más benigna", y para los actos copenados, estimar su realización en la determinación de la pena; mientras SAUER (1955:242) parece aceptar solamente estimar la pena del delito desplazado en la determinación de la del preferente y sólo en los casos de consunción. También en un sentido limitado parece pronunciarse HARTUNG (1954:587s), para quien, en casos de subsidiariedad expresa, la ley desplazzada debiera considerarse no sólo en la determinación de la pena, sino también, de ser posible, como una circunstancia que acredite el carácter culposo o doloso del delito preferente.

"MAURACH (1954a:611) y GEERDS (1961:167, 230s), quien, a pesar de admitir la naturaleza concursal de la institución, afirma esta exclusividad basado en la existencia de lo que él denomina "un único derecho a penar" y en la posibilidad de declarar preferente la ley más levemente penada, posibilidad que resultaría ilusoria de aplicarse en todos los casos el principio de combinación. Una posición más débil mantiene JESCHECK (1955:535s), pues aunque declara la absoluta exclusividad de la ley desplazante, no termina de rechazar por completo la práctica jurisprudencial ya asentada que admitía la combinación de los efectos penales de las leyes concurrentes, remitiendo la cuestión a otra más general relativa a la "interpretación" de la ley.
} 
Desde otra perspectiva, WARDA (1964:92s) afirma que aunque en el concurso (aparente) de leyes también regiría el principio de combinación, éste no podría tener como en el concurso ideal una "validez general", debiéndose examinar la aplicabilidad del "efecto residual de la clase o máximo de la pena del delito más benigno" en cada caso, excluyéndose en particular su aplicación en dos supuestos: a) en los delitos privilegiados, pues en tales casos "transformaría la especialidad privilegiante en su inverso"; y b ) en los actos posteriores impunes en que el acto posterior fuese más gravemente sancionado que el anterior y principal, supuesto en el cual no podrían aplicarse las sanciones del delito en principio desplazado.

También ZIPF (1969:138), desde el punto de vista de la determinación de la pena, propone limitar la aplicación del principio de combinación a los supuestos de delitos privilegiados, extendiendo esta exclusión a los casos de delitos calificados y a los "supuestos de hecho de recogida puros", pues en todos estos casos la ley general o de recogida ya se encontraría comprendida en la ley desplazante ${ }^{12}$.

Actualmente, parece fuera de discusión la aplicación, como regla general, del principio de combinación al tratamiento penal del concurso (aparente) de leyes ${ }^{13}$. Del mismo modo, indiscutidas son las excepciones a esta combinación cuando de ella surgiría una imprevista agravación de la ley preferente y, en principio privilegiada frente al desplazado, como sucedería en ciertos casos de especialidad, subsidiariedad y actos copenados ${ }^{14}$.

\footnotetext{
Aunque no lo declara expresamente, pareciera que guia a ZIPF en esta opinión la "prohibición de la doble valoración", principio básico de la teoría de la determinación de la pena en alemania (cfr. Infra 4.1)

${ }^{13}$ BRUNS (1974:467;1982:166), VOGLER (1979:719), STRATENWERTH (1981:1200), GEPPERT (1982:426), KIENAPFEL (1984.584), BAUMANN/WEBER (1985:665), JESCHECK (1988:670s), SCHÖNKE/ SCHRÖDER/STREE (1991:v. §52/141), DREHER/TRÖNDLE (1993:v. §52/23,50), WESSELS (1993:254), MITSCH (1993:475), y MAATZ (1995:113) -quien, además, considera que en materia de determinación de la pena, el establecimiento de una determinada relación concursal "no tiene influencia"-. Con muy pocas reticencias: Seir (1983:235), VOGLER (1985:v. §52/107,113, 128, 142), BRINGEWAT (1987:77 s). Como "una excepción" plantea todavía SAMSON (1987:v. §52/78) la aplicación de este principio. Por otra parte, STRATENWERTH (1981:1199) llega a plantear incluso una especie de "efecto residual inverso", según el cual sería posible aplicar a la ley desplazante y privilegiada frente a la desplazada, el minimo penal previsto en ésta, si. según las circunstancias del caso, fuese inferior al que resultaria de aplicar aquélla. Oo. Cramer (1970:207), para quien en los casos de "concurso de leyes propio" "sólo debe aplicarse exclusivamente la disposición especial o-en casos de subsidiariedad- la primaria", mientras en aquéllos en que entiende por alguna razón valorativa resulta aplicable el principio de combinación, ya no ve un concurso (aparente) de leyes, sino un "concurso ideal impropio".

CRAMER (1970:107), BRUNS (1974:467), SEIR (1983:235), BRINGEWAT (1987:78), SAMSON (1987:V §52/78), SCHÖNKE/SCHRÖDER/STREE (1991:V. §52/141), MITSCH (1993:475). VOGLER (1985:V. $\S 52 / 107$ ) remite el fundamento de esta excepción a la "prohibición de la doble valoración". Además, SEIR propone extender esta excepción a todos los casos de especialidad, pues respecto a ellos no podría alegarse el argumento de que el autor saldría mejor tratado que si sólo hubiese violado una sola ley-argumento sobre el cual se fundamentó en su origen el principio de combinación-, ya que siempre que se realiza el supuesto de hecho especial se realiza también el general, por la propia estructura lógica de la relación en que se encontrarían. SEIR (1983:236) propone también extender esta excepción a todos los supuestos de subsidiariedad expresa y también a
} 
Por lo mismo, no carece de sentido la afirmación de alguna jurisprudencia y ciertos autores de que, en el sistema penal alemán, en la actualidad, la diferencia entre el concurso aparente de leyes y el concurso ideal estaría "reducida a cero" (SCHÖNKE/SCHÖDER/STREE, STGB KOMMENTAR, MüNICH 1991, V. § 52/104)).

\subsubsection{El "resurgimiento" o "vuelta a la vida" de la ley desplazada (cuando no se aplica la preferente)}

Aunque el "resurgimiento" de la ley desplazada ya había sido expuesto por el propio MERKEL (1877:226), quien afirmaba la ley desplazante operaría como tal sólo en el supuesto de ser efectivamente aplicable al caso, de manera que de faltar algún presupuesto material (p. ej., prescripción) o procesal (p. ej., falta de la preceptiva querella) de la misma, sólo restaba aplicable la ley en principio preterida; esta cuestión no volvió a ponerse de manifiesto sino hasta que pasó a ser dominante la idea de que en el concurso (aparente) de leyes se estaba ante una verdadera concurrencia, aunque sólo de leyes, concurrencia que justificaría no sólo este "resurgimiento" de la ley en principio desplazada, sino también la extensión al mismo de la aplicación del llamado principio de combinación ${ }^{15}$.

Así, en este período, comenzaron a ponerse de manifiesto ciertas situaciones en que la ley en principio desplazada podía "resurgir" [Wiederaufleben ${ }^{16}$. En este período, los casos más destacados de "resurgimiento" eran el castigo por la ley en principio desplazada cuando faltaba algún requisito de punibilidad del delito preferente (prescripción, falta de querella) ${ }^{19}$, se producía el desistimiento del delito preferente en la tentativa calificada ${ }^{18}$, o cuando los partícipes en los actos posteriores impunes no lo eran al mismo tiempo del delito principal ${ }^{19}$.

\footnotetext{
los "indiscutidos" de subsidiariedad tácita, donde el supuesto de hecho subsidiario o de "recogida" represente la misma función que el correspondiente en los casos de subsidiariedad expresa, esto es, expresa exclusión de la ley subsidiaria ordenada por ley. Asi, expresamente, SCHNEIDER (1953:660) y BOCKELMANN (1953:235).

${ }^{16}$ En la traducción española común: "vuelta a la vida" (cfr, v.gr., PEÑARANDA (1991:59)).

${ }^{17}$ NAGLER (1944:v. § 73/p. 549, 552), SCHÖNKE (1951:§ 73/VII, 5), H. MAYER (1953:413) -aunque limitado a los por él denominados actos anteriores y posteriores copenados-

${ }^{18}$ Así, LISZT/SCHMIDT (1932:358 nota 5 in fine), y NIESE (1953:175), quien entiende esta opinión sería también compartida por la jurisprudencia del BGH.

${ }^{19}$ SIEGERT (1933:98) -comentando jurisprudencia en el mismo sentido-, NAGLER (1944:v. §73/p. 551), SCHÖNKE (1951:§ 73/VII, 3), H. MAYER (1953:413). Anteriormente ya habia adelantado un tratamiento similar para estos supuestos HOEGEL (1916:845ss), destacando la imposibilidad de castigar al partícipe del hecho posterior por el principal ya ejecutado y sobre el cual no había prestado su consentimiento. Oo. SCHLOSKY (1942:286), para quien el partícipe en el acto posterior impune no sería punible, pues considera este acto posterior un hecho atipico.
} 15 
Después, por la misma razón de fondo que justificaba el principio de combinación, esto es, porque se entendía que la falta de alguno de los requisitos materiales o procesales para la persecución del delito en principio desplazante, hacía decaer no ya el efecto desplazante, sino la propia idea del concurso (aparente) de leyes, al faltar su presupuesto fáctico, se aceptaba en general el "resurgimiento" de la ley desplazada cuando la desplazante no era aplicable al caso concreto por falta de algún requisito material (prescripción, desistimiento en la tentativa calificada, error sobre una circunstancia especializante, falta de participación en el hecho principal) o procesal (falta de querella en delitos de acción privada) ${ }^{20}$; no faltaron quienes atribuían este "resurgimiento" a una mera cuestión de interpretación de la ley ${ }^{21}$, ni quienes, sin consentirlo del todo, al menos pareceían justificarlo desde un punto de vista políticocriminal $^{22}$, como así tampoco los que lo negaban de plano ${ }^{23}$.

Sin embargo, una vez admitido con carácter más o menos general el "resurgimiento" de la ley desplazada comenzaron a plantearse serias divergencias sobre el alcance que debería dársele al mismo, especialmente cuando la ley en principio desplazada contemplaba una pena más severa que la desplazante.

El primero en preocuparse del tema es SAUER, quien distingue a efectos de admitir o no el "resurgimiento" de la ley desplazada, entre casos de especialidad y casos de consunción. En los casos de especialidad, SAUER (1955:232) admite el "resurgimiento" de la ley general sólo cuando la ley especial no es aplicable por "obstáculos procesales" (falta de querella, prescripción), pero si lo que faltan son requisitos materiales, como sucedería en "el desistimiento del hurto famélico" (supuesto de hecho privilegiado), no admite castigar por el supuesto de hecho general de hurto. En cambio, tratándose de supuestos de consunción -para el autor, actos anteriores, acompañantes y posteriores copenados-, admite SAUER (1955:242) el "resurgimiento" de la ley desplazada en todos los casos en que, "a consecuencia de una causal eximente de la responsabilidad o de un obstáculo procesal" no sea aplicable la

${ }^{20}$ SCHÖNKE/SCHRÖDER (1954:V. §73/VII,5), SAUER (1955:232), JAGUSCH (1957:V. §73/C), VOLL (1958:170), GEERDS (1961:170s), quien de todos modos critica por "equivoca" la expresión "resurgimiento de la ley desplazada". puesto que, en verdad ésta nunca habria sido desplazada, ya que al faltar alguno de los requisitos materiales o procesales para la sanción de la teóricamente desplazante no existiría concurso (aparente) de leyes alguno: KOHLRAUSCH/LANGE (1961: $\$ 73 / 111,3)$, quienes parecen limitarlo a los llamados actos copenados; WARDA (1964:93, 82), quien ofrece similares argumentos a los de GEERDS, llegando incluso a no utilizar siquiera la voz "resurgimiento"; HÄNDEL (1964:1733); BAUMANN (1968:630s), SCHÜNEMANN (1968:119) y WELZEL (1969:234s).

21 JESCHECK $(1955: 536)$.

22 MAURACH (1954a:611, 628, 631), quien sin embargo admite plenamente el "resurgimiento" de la ley desplazada en los llamados actos copenados.

${ }^{23}$ Así se pronuncia BOCKELMANN (1960:625) en relación a los actos posteriores impunes, respecto de los cuales afirma que si el acto principal "no puede sancionarse - o no llega a penarse-, entonces decae también la punibilidad del acto posterior", pues ambos serían sólo "distintas partes de un único [...] suceso vital". 
ley desplazante, fundando en ello la diferencia de tratamiento entre tales supuestos y los de especialidad. JAGUSCH (1957:V. §73/C,1) también reconoce ciertas dificultades para el resurgimiento de la lex generalis, aunque acierta mejor que su antecesor en la causa de las mismas: el absurdo que resulta del "resurgimiento" de la lex generalis cuando la specialis es una figura privilegiada; y de allí que, con razón, no lo admita para este particular supuesto, como tampoco lo estaba haciendo la jurisprudencia del momento. En el mismo sentido se pronuncia GEERDS (1961:174s), tratándose de obstáculos procesales, de falta de querella en delitos de acción privada o de la prescripción de la ley privilegiada, al afirmar que, en estos casos, un "resurgimiento" de la ley general "convertiría en ilusorio el privilegio previsto por la ley" ${ }^{24}$.

Sin embargo, percatándose GEERDS de que con este proceder no se explica suficientemente por qué dejaría de aplicarse la ley general si se cumplen todos sus presupuestos, intenta reconducir este problema a una cuestión interpretativa y afirma que en éste ámbito debe resolverse. A un problema interpretativo remite también GEERDS la cuestión del "resurgimiento" de la ley general, caso que la especial no fuese aplicable por alguna razón material. En estos casos, según GEERDS (1961:171s), la teoría del concurso (aparente) de leyes no se podría oponer a la aplicabilidad de la ley general, pero puede ser que "la misma información según la cual se excluye la ley preferente, también haga inaplicable la desplazada", lo cual sólo sería resoluble desde el punto de vista interpretativo.

Este último raciocinio lo extiende también GEERDS (1961:172s) a los supuestos de los distintos grados de perpetración del delito, argumentando que la "causa de exclusión de la pena" del grado más grave alcanzaría también al más leve, típico ejemplo de lo cual sería el desistimiento del delito cosumado respecto a la tentativa o a los actos preparatorios especialmente punibles, principio aplicable también a las distintas formas de participación en el delito, "donde el desistimiento de la más grạve debe comprender el de la más leve". GEERDS (1961:173) afirma que en estos últimos supuestos no sería la teoría del concurso (aparente) de leyes la opuesta al "resurgimiento", pues ya no se trataría de un problema propio de la misma "sino de uno que tiene que ver con el alcance de las causas de exclusión de la pena". A la "interpretación del caso particular" remite también WARDA (1964:93) las dificultades que se presentan respecto al "resurgimiento" de la ley desplazada, admitiendo, en general, las excepciones propuestas por GEERDS.

\footnotetext{
${ }^{24}$ La exclusión del "resurgimiento" de la ley general, cuando no resulta por alguna razón aplicable la especial privilegiada, y aún la calificada, como p. ej., si tratándose de delitos de acción privada como la violación y otros semejantes, la víctima decide no presentar denuncia o querella para evitar participar en un proceso penal, también es admitida expresamente por alguna jurisprudencia y autores como HÄNDEL (1964:1733), WARDA (1964:93), BAUMANN (1968:631) y WELZEL (1969:234).
} 
Además, a propósito del fallo OLG Braunschweig de 28 de junio de $1963^{25}$, se extiende la polémica relativa al "resurgimiento" de la ley desplazada (y más gravemente penada), cuando, contemplando el delito principal una pena inferior a la del acto posterior copenado que se trataba, existían impedimentos procesales o materiales para aplicarlo. En este caso, y contra la jurisprudencia anterior ${ }^{26}$, falló el tribunal que la destrucción de una cosa previamente hurtada (en un hurto famélico) permanecería como "un acto posterior impune" aunque se excluyese la sanción por el delito principal (falta de hurto famélico) en virtud de la prescripción del mismo. Para ello, argumentó que los actos de apropiación, como la destrucción de la cosa robada, pertenecían al concepto mismo de los delitos de sustracción "con ánimo de apropiarse", y por ello se encontraban "copenados" en ellos. De allí que la prescripción del delito de sustracción respectivo excluye la penalidad del acto posterior de apropiación, pues de otro modo se produciría "un efecto contrario a la voluntad del legislador", más aún cuando tal resultado consiste en sancionar como delito lo que antes era sancionable como falta.

Inmediatamente surgieron críticas y comentarios específicos respecto a esta decisión ${ }^{27}$. Primero fue DREHER (1964:168), quien sin dejar de percatarse del "absurdo" y "grotesco" resultado a que se llegaría de admitir en la especie la sanción por el acto posterior, no parece estar de acuerdo con la vía adoptada por el tribunal para evitarlo, pues por ella también se llegaría a un absurdo, ya que al privársele prácticamente de tipicidad autónoma al acto posterior, no podrían sancionarse a los partícipes en el mismo. Para evitar ambos absurdos, propone DREHER (1964:169) tres vías de solución, decantándose claramente por la última. La primera vía, limitada al caso concreto, sería admitir siempre que no puede entenderse que una falta (hurto famélico) comprenda el injusto de un delito (daños), limitando de este modo el alcance de los actos copenados a aquéllos supuestos en que la pena del delito principal comprenda la del copenado. La segunda, de aplicación a un mayor número de supuestos, estimar que la destrucción posterior de la cosa sustraída podría constituir, en ciertas condiciones, un daño relevante que superaría el previsto en el delito de sustracción respectivo (en el hurto famélico, la destrucción de los envases, por ejemplo), y por tanto, que tal destrucción no constituiría acto copenado o impune alguno, al imposibilitarse con ella la devolución de la cosa apropiada a su legítimo poseedor o a la propia comunidad

\footnotetext{
${ }^{25}$ Publicado en MDR 1964, p. 167.

${ }^{26}$ DREHER (1964:168), quien califica este cambio de "giro en 180 grados"

${ }^{27}$ Sin embargo, algunos autores como WARDA (1964:193) y WELZEL (1969:235) parecen aceptarla sin más; mientras BAUMANN (1968:650) extiende la exclusión del resurgimiento del acto copenado cuando el principal prescribe a todos los casos en que existen impedimentos procesales para castigar el acto principal, con independencia de si el acto copenado contempla menor o mayor pena que aquél.

${ }^{28}$ En este sentido se habia pronunciado antes SAUER (1955:242).
} 
(incluso la destrucción de las cosas propias es punible en ciertas condiciones). Por último, la tercera -y según DREHER "principal" vía de solución-, sería, atendiendo a que el acto principal y el posterior formarían un ente "complejo" en virtud del cual bastaría con la pena del principal para comprender el injusto del hecho, pero seguiría teniendo relevancia penal el acto posterior, especialmente para la sanción de los partícipes, entender que la prescripción para ese "complejo" sólo comenzaría a correr con la finalización del acto posterior, sin que pudiese terminar independientemente para cada acto, sino conjuntamente para ambos, según el más extenso plazo, pues de lo contrario, si una persona sólo realizase el acto posterior su tiempo de prescripción sería mayor que el de quien, además, hubiese realizado el acto principal, resultando de este modo injustamente premiado quien comentiese no uno, sino dos hechos punibles. Critica KOHLMANN (1964:493) esta última vía de solución propuesta por DREHER, alegando que ella no sólo era abiertamente contraria al entonces vigente $\S 67$ IV Cp alemán, sino también al $\S 128$ del proyecto de 1962, disposiciones que establecían ambas, comenzar a contar la prescripción desde el día en que el hecho fuese realizado, obligando por tanto a contar individualmente la prescripción para cada hecho. Sin embargo, la propuesta de KOHLMANN (1964:493s) para solucionar este caso no puede considerarse en sí misma afortunada. En efecto, afirma el autor que, estando prescrita la ley en principio desplazante, ni siquiera existiría concurso (aparente) de leyes, por faltar uno de sus presupuestos: la existencia de un "derecho del estado a la pena" [Strafberechtigun] -según el concepto introducido por GEERDS- respecto de la ley teóricamente desplazante, y, por tanto, tampoco ningún "desplazamiento" del delito de daños por el de hurto famélico. Posteriormente, KRAUB (1965:174ss) criticaría la postura de KOHLMANN rechazando que el concepto de concurso (aparente) de leyes que éste utiliza sea aplicable también a los llamados actos posteriores copenados-teoría diferenciadora estricta-, proponiendo en cambio otra vía de solución basada en preguntarse primero si estamos o no ante un supuesto de actos copenados -entendidos como "unidad valorativa"-, y si la respuesta es positiva, en qué medida modificaría los efectos de tal relación la prescripción del hecho principal. Pero, desde esta perspectiva, KRAUB (1965:180) también criticaría el fallo en cuestión, pues encuentra que si en general ya es "discutible" que "el ánimo de apropiarse" en los delitos de sustracción permita admitir como acto de realización del mismo la destrucción de la cosa sustraída, según afirma el tribunal, respecto al hurto famélico no le cabe duda de que la "apropiación" a que se refiere el supuesto de hecho legal en cuestión no puede tener el amplio alcance que le concede el fallo. En efecto, para KRAUB (1965:180s), el entonces vigente $\S 370$ I Nr. 5 no permitiría a quien hurtase famélicamente realizar cualquier acto de apropiación de la cosa hurtada -como sostenía el fallo criticado-para entender dicho acto uno "posterior impune", sino solamente usar de ella para satisfacer sus necesidades, y nada más: esa sería la razón del privilegio establecido respecto al delito de hurto básico, y el elemento decisivo para su delimitación típica. De allí que según KRAUB (1965:181), no realizando el objetivo previsto en la ley sancionadora del acto 
principal, la destrucción de la cosa hurtada famélicamente nunca debió considerarse un acto posterior impune, por lo que el autor del hurto famélico sería punible también por los daños representados en la destrucción de la cosa, con independencia de que tal hurto prescribiese o no.

Actualmente, este resurgimiento de la ley en principio desplazada es admitido como principio general, en el sentido de que, realizados los presupuestos típicos de las leyes concurrentes, pero a falta de otros requisitos materiales (desistimiento en casos de tentativa calificada, error sobre la circunstancia calificante, falta de participación en el hecho principal, existencia de causa de justificación, exculpación u otra causa personal de exclusión de la pena) o procesales (prescripción, falta de querella o denuncia) que permitan sancionar el hecho según la ley en principio desplazante, sería posible el castigo del infractor en virtud de las disposiciones de la ley en principio desplazada ${ }^{29}$.

Sin embargo, las discusiones surgidas en el período anterior tienden a matizar este principio general, rechazándose el resurgimiento de la ley desplazada en los siguientes supuestos: 1) cuando el "resurgimiento" de la ley en principio desplazada pasa a llevar el privilegio comparativo que resultaría de aplicar la ley en principio desplazante ${ }^{30} ; 2$ ) cuando el resurgimiento de la ley desplazada consiste en el de los estadios previos especialmente punibles comprendidos en la realización de un mismo delito cuya tentativa o consumación se desiste ${ }^{31} ; 3$ ) cuando, tratándose de delitos calificados, podría "resurgir" la ley general por falta de querella o denuncia de la víctima o de cualquier otro impedimento procesal similar que importe pasar a llevar la

\footnotetext{
29 SCHMIDHÄUSER (1975:18/33), VOGLER (1979:720), GEERDS (1981:35), STRATENWERTH (1981:1203), GEPPERT (1982:421), SEIR (1983:232), KIENAPFEL (1984.584), ( VOGLER (1985:V. § 52/113, 128, 142, 145), BAUMANN/WEBER (1985:665,683), BRINGEWAT (1987:79), SAMSON (1987:V. § 52/74), JESCHECK (1988:670s), SCHÖNKE/SCHRODER/STREE (1991:V §52/116,134ss), LACKNER(1993:28), DREHER/TRÖNDLE (1993:V. §52/24, 50), WESSELS (1993:254, 255), MITSCH (1993:475), KÜHL (1994:734), MAATZ (1995:113). Asi también en la jurisprudencia, cfr, v.gr. BGH 22.7.70 (3 StR $237 / 69)$.

${ }^{30}$ SCHMIDHÄUSER (1975:18/33), VOGLER (1979:729ss) [=(1985:V. §52/107,116,129,146)], STRATENWERTH (1981:1204), GEPPERT (1982:422s,426, 429), BLEI (1983:363), BAUMANN/WEBER (1985:684), BRINGEWAT (1987:81), JESCHECK (1988:671), SCHONKE/SCHRODER/STREE (1991:V. §5/136, 139), MITSCH (1993:475)

${ }^{31} \mathrm{El}$ alcance de esta excepción es discutido, pues mientras VOGLER (1979:727s) [=(1985:V§52/130)] SCHÖNKE/SCHRÖDER/STREE (1991:v. §52/139), la limitan a los delitos de peligro previos al de lesión que se desiste; GEERDS (1981:35), STRATENWERTH (1981:1205). MITSCH (1993:475) la extienden a la mayoría de los supuestos de tentativa y actos preparatorios previos, puesto que, afirman, de otro modo perdería bastante sentido la medida político-criminal comprendida en la disposición relativa al desistimiento. En este último sentido, cfr. BGH 21.1.93 (4 StR 638/92), publicado en JR 94, 71 con comentario crítico de GEEPERT (1994:73), quien sostiene, en estos casos debe limitarse el efecto del desistimiento al delito de peligro concreto anteriores al mismo, excluyendo la posibilidad de extenderlo a los delitos de peligro abstracto que se hubiesen realizado.
} 
voluntad de la víctima de no comparecer en juicio ${ }^{32}$; y 4) cuando, tratándose de actos posteriores copenados cuya pena sea mayor que la del principal, la punibilidad del acto principal es materialmente posible, pero por alguna razón de carácter procesal como falta de querella de la víctima, prescripicón, etc., no se produce en los hechos ${ }^{33}$.

\subsection{3.. La participación de terceros (aplicación a éstos de la ley en principio desplazada)}

Un caso particular de resurgimiento de la ley en principio desplazada dice relación con el tratamiento penal de los terceros partícipes en el hecho cuando por alguna razón no resultan punibles por la ley desplazante, lo cual sucedería ejemplarmente en la participación en los llamados actos posteriores impunes. La imposibilidad de castigar en tales supuestos a los partícipes conforme al hecho principal en el que no hay consentido, condujo a la doctrina a formalizar este efecto, atribuyéndole un "carácter personal" al concurso (aparente) de leyes para justificar el distinto tratamiento que recibirían autores y cómplices. El primero en destacar este "carácter personal" fue MAURACH, aunque no referido al concurso (aparente) de leyes en general, el cual limitaba a los supuestos en unidad de acción, sino sólo a los llamados actos previos y posteriores copenados. Para MAURACH (1954a:626), en los actos copenados concurrirían hechos "aisladamente punibles", "pero que en una consideración conjunta son retribuídos por la punición del hecho principal". Según MAURACH (1954a:628, 631), esta "retribución conjunta" constituiría una "causa personal de exclusión de la pena", una especie de "suspensión de la pena" condicionada "por la concreta punibilidad y real punición del hecho principal", lo cual tendría como efecto la posibilidad de sancionar por el acto copenado a los partícipes que no lo son del acto principal, estimar en sentido agravatorio la realización del acto copenado a la hora de determinar la pena del principal y, por supuesto, la posibilidad de aplicar la sanción del acto copenado caso que no pudiese aplicarse, por cualquier motivo, la del principal $^{34}$. Posteriormente, y siguiendo la línea jurisprudencial, JAGUSCH (1957:V. $\S 73 / C$ ) afirmaría que en todos los supuestos de concurso (aparente) de leyes, la

\footnotetext{
${ }^{32}$ VOGLER $(1979: 730)$ [=(1985: $\left.\left.§ 52 / 115\right)\right]$. STRATENWERTH (1981:1205), BAUMANN/WEBER(1985:665), DREHER/TRÖNDLE (1993:V. §52/24). Oo. SCHÖNKE/SCHRÖDER/STREE (1991:v. §52/116), quien declara expresamente la posibilidad de castigar por la ley general en caso que la especial decaiga por algún impedimento procesal.

33 VOGLER (1979:731) [=(1985:v§52/145), STRATENWERTH (1981:1204), Blei (1983:363), BAUMANN/WEBER (1985:684), BRINGEWAT (1987:91s), SAMSON (1987:v. §52/74), JESCHECK (1988:669s), SCHÖNKE/SCHRODER/STREE (1991:v. §52/116s), Dreher/Tröndle (1993:v. §52/50), LACKNER (1993:v. §52/32). Oo. WESSELS (1993:255) quien parece no admitir excepción alguna a la punibilidad del acto posterior copenado cuando la del principal se hace imposible por alguna causa de carácter procesal

${ }^{34}$ Oo. BOCKELMANN (1960:625) para quien, dado que entiende el acto posterior y el anterior como un "único suceso vital", la punibilidad de los partícipes en el acto posterior copenado sólo puede fundamentarse en su participación en el hecho principal.
} 
decisión de admitirlo o no sería una cuestión "perteneciente a la culpabilidad", con lo cual le atribuía una ubicación dogmática que presuponía al menos la concurrencia típica y, además, le otorgaba a la misma un carácter altamente personal, dado que las cuestiones relativas a la culpabilidad del autor no influirían, en principio, en la determinacación de la pena de otros partícipes en los hechos que se juzgasen. Por su parte, GEERDS (1961:176, nota 147, 229), admite por una parte la ubicación del concurso (aparente) de leyes en la culpabilidad, como proponía JAGUSCH, y además, extiende la propuesta de MAURACH a todos los supuestos de concurso (aparente) de leyes, atribuyéndole al mismo "una naturaleza altamente personal", "en tanto que el efecto del concurso de leyes corresponde en los hechos a una personal causa de exclusión de la pena" ${ }^{35}$, por lo cual afirma que, al igual que en los restantes supuestos concursales, debe ser examinada "particularmente respecto a cada autor y partícipe".

Hoy en día, en cuanto a la participación de terceros, como caso especial de resurgimiento de la ley en principio desplazada, se admite en general la posibilidad de castigarlos por el delito en principio desplazado, cuando no concurren en ellos los presupuestos que permiten su desplazamiento en relación al castigo del autor principal, especialmente respecto de los denominados actos posteriores copenados, aceptándose así, en los hechos, el "carácter personal" que a la institución le otorgara GEERDS en el período anterior ${ }^{36}$.

\subsection{Tratamiento del problema en la dogmática española}

\subsubsection{Los (efectos residuales) de la ley en principio desplazada (o su aplicación en conjunto con la preferente)}

A pesar de la importancia práctica de la materia, este punto no es abordado expresamente por la inmensa mayoría de los autores españoles ni por la jurisprudencia del TS hasta bien entrada la década de 1980. Cabe de ello concluir que, en general se admite hasta ese fecha que el tratamiento penal del concurso (aparente) de leyes se

\footnotetext{
${ }^{35}$ Sin embargo, GEERDS (1961:165) no admite, como MAURACH respecto del acto copenado, estimar la ley desplazada en la medida de la pena del delito principal.

SCHMIDHÄUSER (1975:18/33), PREISENDANZ (1978:V. §52/III,2e), KÜHL (1978:476), VOGLER (1979:720), STRATENWERTH (1981:1206), GEPPERT (1982:429), BLEI (1983:363), KIENAPFEL (1984.584), VOGLER (1985:V. §52/145), BAUMANN/WEBER (1985:683), BRINGEWAT (1987:82) SAMSON (1987:V. § 52/75), JESCHECK (1988:670), SCHÖNKE/SCHÖDER/STREE (1991:V. § 52/1189), DREHER/TRÖNDLE (1993:V. §52/50). El fundamento de este efecto difiere de unos a otros: mientras para STRATENWERTH este tratamiento diferenciado entre autores y participes correspondería a la aplicación, en materia concursal, del llamado principio de accesoriedad limitada; BLEI Y PREISENDANZ lo fundamentan respecto a los actos posteriores copenados, en el carácter de "causa personal de exlusión de la pena" que antes MAURACH le habia atribuído a éstos
} 
regiría por el principio de la aplicación de la ley preferente con total exclusión de la ley desplazada, atendida la supuesta incompatibilidad existente entre ambas y el carácter de problema interpretativo que le atribuye a la institución la doctrina dominante ${ }^{37}$.

De allí que el número de quienes se preocuparan del dominante en Alemania principio de combinación fuera reducido, aunque es significativo que hubiesen sido principalmente los monografistas de la materia y algún que otro tratadista, incluyendo un miembro del $\mathrm{TS}^{38}$, pero no siempre para admitirlo, como puede verse en SANZ (1986:127), quien rechazaba expresamente la posibilidad de aplicar este principio en España, pues tal respuesta penal al concurso (aparente) de leyes provocaría "una total imposibilidad de distinción entre el sentido propio del concurso de normas y el del concurso efectivo"; y en GARCíA ALBERO (1995:191), quien reproduce los mismos argumentos e insiste en que los casos de concurso (aparente) de leyes, sólo se cometería un delito y, por tanto no podría aplicársele el régimen penal del concurso ideal, donde se cometen dos o más delitos. También en contra de la aplicación del principio de combinación, se pronuncia CUERDA (1992:225), para quien tal tratamiento penal era "innecesario e indamisible", pues el entonces vigente art. 68 CP acogía "indudablemente el principio de absorción simple, lo que quiere decir que las penas de los preceptos desplazados no pueden tener ninguna eficacia. $Y$ si se pretende que la tenga para perjudicar al reo-agrega CUERDA- [...], se está infringiendo paladinamente el principio de legalidad" ${ }^{39}$.

Por el contrario, CUello CONTRERAS (1979:469s) admite casi sin discusión el principio de combinación como tratamiento penal del concurso (aparente) de leyes, trasladándolo directamente de la doctrina alemana dominante en la época al sistema español, con el argumento de que el art. 68 CP no establecía otra cosa que "la idea de que la pena habrá de tomarse del tipo penal predominante", pero que "el principio de absorción es modificado por el de combinación", en el sentido que no se excluiría totalmente la ley preterida, sino que ésta podría tomarse en cuenta, en virtud del principio del efecto residual de la ley más benigna, en el caso que "posea un marco

\footnotetext{
${ }^{37}$ Explicitamente, afirmaban el tratamiento penal del concurso (aparente) de leyes supondría la aplicación exclusiva de la ley preferente SANZ (1986:127), CONDE-PUMPIDO (1990:199) y SÁINZ (1990:371), agregando todos ellos en que tal tratamiento traduciria, en el plano de los efectos penales, la diferencia existente entre el instituto estudiado y el llamado concurso ideal. Lo mismo sostenía BACIGALUPO (1990:274), aunque en la práctica admitía la necesidad de estimar la ley preterida en la determinación de la pena de la ley preferente, según se explica arriba en el texto.

${ }^{38}$ Así, entre los monografistas, SANZ (1986:127); PEÑARANDA (1991:55ss); CUERDA (1992:217ss); y GARCíA ALBERO (1995:185ss). Y entre los tratadistas, BACIGALUPO (1990:274)-aunque en vez de combinación habla de absorción-; y MIR (1990:737).

${ }^{39}$ Enfrentado a un caso práctico, MORILLAS (1992b:162) también está por rechazar la aplicación del principio de combinación de los marcos penales en el concurso (aperente) de leyes. Oo. SUÁREZ MONTES (1983:1290), quien, en otro caso concreto, sugiere hacer valer la ley desplazada en la determinación de la pena definitiva, a través del entonces vigente art. 61. En el mismo sentido, MARTÍNEZ GONZÁLEZ (1988:95).
} 
penal con el límite inferior más severo que el tipo predominante, o que contenga efectos penales consecuencias secundarias o medidas de seguridad de las que éste carezca".

Por otro lado, BACIGALUPO $(1990: 274,277)$, a pesar de afirmar primero que "la consecuencia práctica del concurso de leyes reside en que sólo es aplicable la pena del delito que desplaza a los otros $y$, además, en la determinación de esa pena no deben computarse otras violaciones de la ley" [el subrayado es del autor], lo que marcaría "una diferencia fundamental con la consecuencia jurídica del concurso ideal", regulado según él por el art. 68, termina por admitir que la ley en principio desplazada despliegue algunos efectos, como en los supuestos de consunción, que estima serían regulados por el art. $71 \mathrm{CP}$, interpretación contra la cual "no podría alegarse que el art. $71 \mathrm{CP}$ establece la aplicación de la pena del delito más grave en su grado máximo, lo que sería inconsecuente con la idea fundamental del concurso de leyes... [. pues] tanto en los concursos aparentes como en el concurso ideal se debe contemplar en la pena del hecho sancionado la doble (múltiple) tipicidad " [el subrayado es mío]. Postriormente, vuelve BACIGALUPO sobre el tema, afirmando la posibilidad de combinar los efectos penales de las leyes concurrentes en dos sentidos: primero en la forma de un "efecto de cierre" del límite mínimo del marco penal aplicable el de la ley en principio desplazada, si es mayor que el de la preferente, porque "la lesión de más de una ley penal... no puede ser motivo de reducción del mínimo de la pena prevista para uno de los delitos" [STS 6.4.88, Ponente: BACigalupo (A. 2473) ] ; y segundo, y en todo caso, apreciándose en la determinación de la pena del delito preferente "la doble (múltiple) tipicidad" [BACIGALUPO (1990:277)].

Siguiendo la doctrina fijada en la STS que se cita, admiten posteriormente el "efecto de cierre", GONZÁlez PULIDO (1989:194), LÓPEZ BARJA (1991:168), y ZUGALDíA (1993:315), aunque con algunos matices. Así, mientras GONZÁLEZ PULIDO (1989:195) ve en este "efecto de cierre" un principio aplicable incluso a los casos de los llamados delitos calificados por el resultado, para evitar en ellos absurdos beneficios; LÓPEZ BARJA (1991:169) sostenía que, descontando "la bondad de la regla" para los casos de concurso (aparente) de leyes, ésta no podría aplicarse a los casos de concurso ideal, "si la comparación de las penas ha de hacerse en concreto -...- y no en

\footnotetext{
${ }^{40}$ En el caso de la sentencia citada, se trataba de un supuesto de concurso entre contrabando y tráfico de drogas en que el tribunal de instancia había condenado por contrabando -concurso (aparente) de leyes- y aplicado la facultad discrecional de rebaja de la pena que permitia el art. 2 de la ley de contrabando, con lo cual la pena resultó inferior a la permitida en el marco minimo del párrafo 2 del art. $344 \mathrm{Cp}$. El TS casó la sentencia con el argumento arriba expuesto y declaró la existencia de "un "efecto de cierre" que la pena mínima más grave tiene tanto en los concursos ideales como en los concursos aparentes". Una posterior aplicación de este (efecto de cierre) vio BACIGALUPO (1989:51ss) en la relación existente entre el aborto seguido de muerte y lesiones y las figuras culposas o dolosas de homicidio y lesiones -cosa que a PEÑARANDA (1991.58 nota 42) no le convence mucho-, y en otros casos que considera propiamente de concurso ideal, como hace en la STS 8.10.91 (A. 7586). de la cual también es ponente.
} 
abstracto", como habría hecho erróneamente la sentencia de instancia casada en la STS citada. Por su parte, ZUGALDíA (1993:316) extiende el "efecto de cierre" también al tratamiento de la concurrencia entre una figura frustrada (homicidio) y las lesiones gravísimas que de dicho intento se sigan, admitiendo preferente el delito frustrado de homicidio, pero limitando la pena del mismo al límite inferior del marco penal de las lesiones efectivamente producidas. Posteriormente, PEÑARANDA (1991:58) también admite los efectos del principio de combinación en la fijación del marco mínimo penal aplicable, la aplicación de las penas accesorias y pecuniarias de la ley desplazada, y en la determinación de la pena aplicable en definitiva, pero señala que respecto al CP 1944, la cuestión no tendría "gran interés", por el sistema de penas seguido, que impedía el solapamiento de marcos penales, aunque reconoce un caso significativo podría ser el de la citada STS 6.4.88.

Sin embargo, precisamente en contra de lo resuelto en la sentencia arriba citada se pronuncia también CUERDA(1992:225s), para quien la aplicación a este caso del llamado principio de combinación deriva de un problema -la diferencia de marco penal mínimo entre las normas en juego- que para él era, "en realidad, inexistente", pues si en vez de haberse comparado los marcos penales "en abstracto", esto es, sin tener en cuenta los grados de ejecución y participación ni las circunstancias del hecho, se hubiesen comparado las penas "en concreto", esto es, aquéllas determinadas circunstanciadamente para cada uno de los delitos posibles, no se habría presentado "ninguna dificultad en materia de límites de marcos, sencillamente porque lo que se compara son cantidades exactas y concretas de pena, con el objeto de elegir la más grave", comparación en concreto que, según el autor "se deriva" del "tenor literal" del mencionado art. 68, al ordenar éste sancionar por aquel precepto "que aplique la mayor sanción al delito o falta cometidos" ${ }^{41}$ [el subrayado es del autor]. Aunque la jurisprudencia que cita CUERDA (1992:224 nota 129) no es del todo clara, como él mismo reconoce, en la STS 25.1.90 (A. 1010) el modelo de comparación concreta que propone aparece claramente expuesto y fundado en similares razones ${ }^{42}$.

Por su parte, MIR (1990:737), aunque expone someramente la cuestión conforme la entiende la doctrina alemana dominante, no parecía decidido a admitir la

\footnotetext{
${ }^{41}$ En este mismo sentido se habían pronunciado antes CUELLO CALÓN/CAMARGO (1981 1,20:711s) al afirmar que la gravedad de la pena habría de determinarse, si es necesario, "también cuando su agravación resultare de la aplicación de circunstancias agravantes", excluyendo con ello su apreciación en abstracto.

${ }^{42}$ Según esta sentencia, muy posterior a la criticada de 6.4.86 (A. 2473), "el artículo 68 del Código Penal regula el llamado concurso de leyes o normas, a través o mediante el sistema de alternatividad en el sentido de elegir, entre los distintos preceptos que sean utilizables, aquél que aplique mayor sanción al supuesto concreto de delito o falta que se trate, lo cual supone apreciar primero el juego penológico del artículo 61 del mismo Cuerpo legal y después decidir, de tal manera que, en consecuencia, se aplique la pena más grave en concreto aunque ésta nazca de aquella sanción penal que teóricamente o en abstracto no sea la más importante en su máximo, porque de hacerse de otra manera se desnaturalizaria el instituto concursal de leyes o normas que tienen una finalidad agravatoria nacida de la comparación punitiva entre dos o más preceptos".
} 
aplicación del principio de combinación durante la vigencia del CP 1944, pero sugirió hacerlo en sus Notas al Tratado de JESCHECK [MIR (1981-II:1042)], en relación al Proyecto 1980, para el caso del robo con fuerza tentado en concurso con un hurto consumado, posibilidad que parece subsistir en el actual CP 1995 si el hurto es alguno de los señalados en el art. 235 y la tentativa de robo con fuerza es la simple del art. $240^{43}$.

\subsubsection{El resurgimiento de la ley desplazada}

En la doctrina y jurisprudencia española anterior a 1980 exisitó de hecho una mayor preocupación respocto al problema del resurgimiento de la ley desplazada, cuando por cualquier razón no es aplicable al supuesto de hecho concreto la ley en principio preferente.

Así, PUIG PEÑA (1952:845ss) [=(1955:84, 107s, 94)] se plantea la cuestión, pero sólo la acepta expresamente en los casos de subisidiariedad ${ }^{44}$, excluyéndola del mismo modo en los de especialidad y alternatividad ${ }^{45}$, por lo que se podría entender la admite implícitamente para los de consunción ${ }^{46}$. Por su parte, CÓRDOBA (1972:331), parece aceptar también este resurgimiento, ofreciendo para ello el ejemplo del resurgimiento del delito de allanamiento de morada del art. 490 cuando el autor de un robo con fuerza en las cosas era uno de los parientes nombrados en el art. 564 -excusa legal absolutoria $^{47}$. También se admite por RODRíGUEZ MOURULLo (1978:157ss) el resurgimiento de la ley desplazada cuando ésta es la figura básica que se consuma en los casos de tentativa calificada con desistimiento, como sería el intento de asesinato desistido después de provocadas lesiones a la víctima. $Y$ finalmente, CUELLo CONTRERAS (1979:469s), admite la posibilidad de aplicar la ley en principio desplazada en los mismos términos de la doctrina alemana dominante en el período, esto es, "si el tipo predominante no puede aplicarse porque, por ejemplo, concurre una causa personal de exclusión de la punibilidad, o porque se trate de un delito perseguible a

${ }^{43}$ Oo. lo visto Supra 7.1 , respecto a la posición de GIMBERNAT de no considerar en concurso (aparente) de leyes,
sino ideal, los casos de tentativia calificada como el expuesto, concidentemente con el tratamiento que les daba la
doctrina alemana.
${ }^{44}$ PUIG PEÑA (1955:83s) cita el caso del resurgimiento de la apropiación indebida del art, 535 cuando falta alguno
de los requisitos de la malversación de caudales públicos del art. 399, apoyado en sentencias anteriores al Cp 1944
(SSTS 27.04 .43 y 8.05 .44$)$.
${ }^{45}$ Aunque PUIG PEÑA (1952:450s) [=(1955:123)] matiza este punto, admitiendo que en ciertos casos sí resurgiría
la ley preterida, pero no se trata de casos que él denomine de alternatividad, sino de los supuestos de
alternatividad que ét trata dentro de lo que llama principio de mayor gravedad punitiva.
${ }^{46}$ Así, expresamente, MIR (1990:737 nota 46$)$.
${ }^{47}$ Ejemplo que antes ya había aparecido en PUIG PEÑA (1955:80). 
instancia de parte y la víctima no quiere hacer uso de la facultad que la ley le otorga". con la excepción del caso en que la ley preferente estableciese un privilegio.

Por lo que toca a la jurisprudencia del TS, en lo pocos casos que aborda el problema también admite en general la posibilidad de castigar por la ley en principio desplazada si la eventualmente preferente no es aplicable por alguna razón material o procesal $^{48}$. En cuanto a las limitaciones a este resurgimiento, la STS 19.5 .65 (A. 2478) desestima que pueda serlo la falta de denuncia o querella del afectado cuando éste no quiera comparecer en juicio, admitiendo que los Tribunales podían pronunciarse sobre un delito de escándalo público aunque faltase la denuncia para proceder por los abusos deshonestos que son origen del escándalo perseguido. Pero en lo que puede considerarse una novedad propia del particular sistema español, rechaza la STS 6.12.74 (A. 5110) la posibilidad del resurgimiento del delito de injurias basado sólo en la ofensa al honor cuando se ha desestimado el de calumnias por no ser falsa la imputación que se trata. La novedad a que me refiero no radica tanto en que se impida el resurgimiento del delito menos grave, ya que con ello no se rompería un privilegio, sino a que, en el fondo, el Máximo Tribunal impide que resurja el delito de injurias porque efectivamente se pasaría a llevar un privilegio, pero no uno penal, sino procesal, el cual no es otro que la exceptio veritatis, posible de invocar si se considerase configurada la figura de calumnias, pero imposible de argüir en un proceso por injurias.

También desde esta perspectiva son interesantes las SSTS 5.12 .56 (A. 3702) y 26.2.67 (A. 591), donde se resuelve expresamente que la aplicación de las reglas del concurso (aparente) de leyes dependen de lo que se decida, independientemente, en cuanto a la participación criminal, esto es, que se afirma indirectamente el carácter personal del instituto. Sobre todo es interesante la primera de las resoluciones citadas pues en ella se establecen dos puntos trascendentes: primero, que la inhumación ilegal posterior a un asesinato puede considerarse, y de hecho así se hace en la sentencia referida, como un acto de encubrimiento del delito contra la vida; y segundo, que al que sólo tiene participación en aquel acto posterior de encubrimiento, debe castigársele precisamente por encubridor de asesinato y no como coautor de un delito de inhumación ilegal, a pesar de que, aunque no aparece claramente en el extracto, al autor del delito de asesinato se le condena también por el de inhumación ilegal ${ }^{49}$. Posteriormente, y en el mismo sentido, la STS 15.11 .77 (A. 4336), aunque no admite

${ }^{48}$ cfr. SSTS 10.7 .54 (A. 1770), donde se admite el castigo por la falta de malos tratos de obra al faltar el animus injuriandi para transformar dichos maltratos en el delito de injurias; y 19.5 .65 (A. 2478), donde se estima improcedente castigar por el delito más grave -abusos deshonestos-y sólo se admite el castigo por el de menor cuantía -escándalo público-, al faltar la denuncia o querella preceptiva para accionar por el primero.

${ }^{49}$ Esto se ve ratificado por sentencias posteriores donde se afirma categóricamente que la inhumación ilegal no puede estimarse un acto de autoencubrimiento posterior a un delito contra la vida, como aparece en las SSTS 8.10 .47 (A. 1141), 22.12.47 (A. 1499) y 15.11 .77 (A. 4336). 
pueda considerarse la inhumación ilegal posterior a un delito contra la vida un acto de autoencubrimiento o agotamiento impune de éstos, admite al menos que de serlo, lo sería sólo "para el procesado [...] condenado por los dos delitos, pero no para el procesado [...] al que sólo se le imputa el de inhumación ilegal", consintiendo con ello en que la posibilidad de un resurgimiento de la ley desplazada sólo respecto al tercero participantes que no lo ha sido del delito principal y preferente, $O$, en términos de GEERDS, el carácter personal del concurso (aparente) de leyes.

A partir de la década de 1980 , el resurgimiento de la ley desplazada parece aceptarse por la mayoría para los casos de subsidiariedad, llegando incluso algunos a definir el alcance de ésta precisamente en virtud de la posibilidad del referido resurgimiento de la ley desplazada, pero en general este efecto no es reconccido expresamente ${ }^{50}$. De esta forma sólo lo reconoce un limitado número de autores, aunque con diversos matices.

Una primera aproximación expresa a esta problemática es la de SANZ (1986:127), quien niega en principio el resurgimiento de la ley desplazada para evitar la impunidad en los casos que falte la querella para proceder por la ley preferente, o no se den las condiciones objetivas de punibilidad de ésta, o se encuentre prescrita, "etc."., con el argumento de que en tales casos no hay un resurgimiento de la ley desplazada, sino que falta propiamente la "verdadera concurrencia de normas", que se daría sólo "si todos los preceptos penales violados reúnen los correspondientes requisitos materiales y formales". En verdad, en este punto lleva razón SANZ, aunque con ello no se niega la idea del resurgimiento de la ley en principio desplazada, que se admite, sino el carácter meramente interpretativo que se le atribuye al concurso (aparente) de leyes, al exigir para su configuración "una verdadera (concurrencia) de normas", esto es, una propia situación concursal ${ }^{51}$.

En cuanto a su reconocimiento implícito, éste puede apreciarse en las definiciones y casos de subsidiariedad
citados Supra 8.2 .2 y, particularmente, en quienes identifican la subsidiariedad como un principio destinado a
evitar la impunidad que resultaria de la no aplicación de la ley principaly, en principio, preferente, como hacen en
general QUINTERO (1989:647); MUNOZZ CONDE/GARCIA ARÁN (1993:415); LUZÓN CUESTA (1994:276s),
y señalando los casos de falta de "alguna condición del tipo" o de "un elemento de la punibilidad -denuncia
previa, por ejemplo-", CONDE-PUMPIDO (1990:200).
51
Naturalmente, si se admite como presupuesto del concurso (aparente) de leyes la existencia de una verdadera
situación concursal, la conclusión que obliga a admitir el resurgimiento de la ley desplazada es casi necesaria por
sí misma. Sin embargo, el problema que resulta de rechazar a priori la institución del resurgimiento de la ley
desplazada, habiéndose admitido el carácter concursal del concurso (aparente) de leyes, es que así no se analizan
los límites que se han impuesto a la misma, en particular, los que se refieren a la imposibilidad de pasar a llevar un
privilegio penal o la voluntad de la víctima, cuando ésta no quiere comparecer ante un tribunal criminal, según
sostenia la doctrina alemana de la época. Este mismo problema surge entre quienes, como los citados en la nota
anterior, aceptan el resurgimiento de la ley desplazada en todos los casos de subsidiariedad, sin plantearse las
posibles limitaciones del mismo. 
Por su parte, MIR (1990:737, notas 46 y 47$)$ toca el punto, pero parece no querer innovar en cuanto a los supuestos que en el período anterior se habían admitido, reconociendo los casos en que PUIG PEÑA sostenía operaría -subsidiariedad y consunción- cuando "el precepto preferente deja de serlo (así, por ejemplo, si es indultado el delito previsto por el delito preferente y no lo es el otro)", y también los de tentativa calificada desistida, admitidos antes por RODRíGUEZ MOURULLo, en los que afirma "la subsistencia del delito consumado constituído por la tentativa" poniendo como ejemplo el resurgimiento de las lesiones dolosas en caso de desistimiento del asesinato. Sin mayores inconvenientes, admiten también el resurgimiento de la ley desplazada en caso de tentativa calificada desistida BUSTOS/HORMAZÁBAL (1994:168), quienes ofrecen además el ejemplo de quien desiste del robo después de realizada la coacción.

Respecto del resto de los supuestos de resurgimiento de la ley desplazada, aunque PEÑARANDA (1991:59ss, 71ss) menciona explícitamente entre ellos los casos de prescripción de la ley preferente, incumplimiento de alguna condición objetiva de perseguibilidad o existencia de una causa personal de exclusión o de levantamiento de la pena (desistimiento de la tentativa, por ejemplo), parece estar de acuerdo solamente en estos últimos casos, en particular tratándose del desistimiento de la tentativa calificada, pues en cuanto al resto de los casos señalados, sostiene PEÑARANDA todavía existen "importantes discrepancias" que harían preferible no tomar una determinación definitiva al respecto. En contra de esta postura algo neutral respecto al tema, GARCíA ALBERO (1995:196ss) es el único autor de este período que admite abiertamente la mayor parte de los casos de resurgimiento de la ley desplazada que admitía la doctrina alemana dominante en este período, a saber, cuando faltaba la punibilidad de la preferente por alguna causa personal (p. ej., desistimiento en la tentativa calificada), cuando falta algún requisito de perseguibilidad del delito preferente (denuncia, querella u otro obstáculo procesal o material -condición objetiva de punibilidad, p. ej.-), y cuando el delito preferente prescribiese antes que el desplazado. En todos estos caso, admite también GARCíA ALBERO las mismas excepciones que plantea la doctrina alemana dominante, esto es, básicamente, la imposibilidad del resurgimiento de una ley cuando con ello se pasa a llevar el privilegio que importa la ley en principio preferente, o el interés de la víctima en no incoar un juicio criminal, si la facultad de querellarse o denunciar se ha establecido precisamente en razón de ese interés.

Sin embargo, al tratar problemas del error en torno al concurso (aparente) de leyes $^{52}$, admite PEÑARANDA (1991:145, 173ss) otros casos de resurgimiento de la ley en principio desplazada, como el que se produce cuando el autor yerra sobre el elemento

\footnotetext{
52 Incidentalmente había tratado el punto, pero sin vincularlo claramente a la teoría del concurso (aparente) de leyes, sino a la disputa entre la determinación de lo que seria un delicta sui generis y uno meramente agravado de un tipo básico, MAQUEDA (1983:703ss)
} 
especializante del supuesto de hecho, en que estima aplicable la sanción a título doloso del delito básico realmente cometido, y en los supuestos de exceso del autor principal sobre lo acordado con el partícipe, cuando este exceso importa una modificación de la figura delictiva a otra especial y más grave, entendiendo aplicable al partícipe sólo la sanción por la figura "desplazada" sobre la que recaía efectivamente el acuerdo ${ }^{53}$. Estos supuestos de resurgimiento de la ley en principio desplazada son negados por GIMBERNAT (1992:840S, 843), pues según él, en los casos de concurso (aparente) de leyes la delimitación interpretativa entre las normas en juego originaría que al desplazarse una ley por otra sólo se comete un delito en la realidad, el preferente. Así, el entonces vigente art. 6bis a) establecería una "regla de determinación de la pena" que obligaría a castigar a quien yerra sobre el elemento típico especializante "como si" ese elemento "no se hubiera dado en la realidad"; y en segundo término, de que del mismo modo, dicho art. 6bis a) establecería como "regla de determinación de la pena" que al partícipe "se le haga responder como si únicamente hubiera colaborado en el tipo residual [o desplazado]". Sin embargo, aunque los argumentos de GIMBERNAT han tenido eco en alguno de sus discípulos ${ }^{54}$, es indudable que resulta al menos dudoso, desde el punto de vista principio de la prohibición de la analogía que extiende el ámbito de lo punible a casos no previstos en el supuesto de hecho legal, sostener que la propia ley quiere castigar a alguien como si hubiese cometido un delito "que no se ha cometido en la realidad" $"$.

En lo que toca a la Jurisprudencia, ésta, al igual que en el período anterior. admite el resurgimiento de la ley en principio desplazada en los casos que se le presentan, aunque, naturalmente, sin recurrir expresamente a esta categoría dogmática. Así, en un caso que estima aplicable el art, 68 CP. la concurrencia entre el delito de peligro de conducción bajo la influencia de bebidas alcohólicas y la imprudencia temeraria, declaró en STS 7.7.89 (A. 6125), que, al faltar la prueba sobre la relación causal entre el estado de ebriedad y la colisión que produjo los daños enjuiciados, esto es, una condición material para castigar por el delito en principio preferente, "la absolución por el delito de imprudencia abre la posibilidad de la condena por el delito de peligro". Y cuando, en virtud del indulto otorgado en el Real Decreto de 25.11.75, debió el Máximo Tribunal sobreseer a un encausado por el delito de alzamiento de bienes, estimó en STS 3.12 .90 (A. 9387) que la falsedad mediante la cual se había perpetrado el delito indultado, podría llegar a resurgir y castigarse

\footnotetext{
${ }^{53}$ Y 10 mismo sostiene PEÑARANDA (1991:175ss) es aplicable a los casos de déficit del autor principal respecto al partícipe, como sería el caso de quien comete un hurto cuando ha sido inducido a un robo -para el partícipe resurge el tipo de hurto en principio desplazado por el de robo-, o no comete el delito inducido porque su ejecución ha quedado en grado de tentativa -la tentativa del delito inducido resurge para castigar al partícipe-.

${ }^{54}$ SÁNCHEZ Tomás (1993:688ss).

${ }^{55}$ Con más argumentos, cfr. la crítica de GARCíA ALBERO (1995:107ss)
} 
independientemente, pero que tal cosa no sucedía en el caso concreto, pues a dicha falsedad también alcanzaban los efectos del indulto en razón de la pena que le hubiese correspondido, y aún los de un indulto posterior, en la especie, el del Real decreto de 14.3.77. Ahora bien, en lo que toca a las limitaciones del resurgimiento, el Máximo Tribunal ha operado con criterios diversos, tendiendo más bien a reducir el ámbito de estas limitaciones. Así, aunque en STS 23.12.92 (A. 10327), se afirma que si se ha juzgado y absuelto a una persona por el delito de alzamiento de bienes que habría sido cometido mediante una falsadedad documental, no puede iniciarse nuevo juicio para castigar por el delito de falsedad documental a la persona absuelta en el proceso por alzamiento de bienes, sin pasar a llevar la cosa juzgada, entiende que esta institución limita, a mi entender acertadamente, la posibilidad de hacer resurgir la ley en principio desplazada sólo cuando para el caso que este se admita en el mismo juicio donde se declara inaplicable la ley en principio preferente. Que el Tribunal lleva toda la razón en ello lo demuestra la simple constatación que practica en la sentencia citada: "Por los mismos hechos ya enjuiciados e imputadas a una misma persona, no cabe acusar a ésta después en otra causa distinta con el subterfugio de pretender que se trata del ejercicio de distinta acción penal porque se le acusa por delito diferente".

Sin embargo, si con la sentencia citada el TS establecía un claro límite al resurgimiento de la ley desplazada, en las STS 30.6.81 (A. 2937) y 22.12.87 (A. 9822), no admite como tal el que se pase a llevar el privilegio de la excusa legal absolutoria, ni tampoco el sobrepasar la voluntad de la víctima de no denunciar el delito desplazante, respectivamente. No obstante, estas resoluciones son explicables desde el punto de vista práctico, en atención a las consideraciones de "justicia material" que parecen haberlas motivado.

En efecto al pasar a llevar el efecto privilegiante de la excusa legal absolutoria, la STS 30.6.81 (A. 2937) lo hace precisamente porque está en contra de la existencia misma de dicha excusa como privilegio penal, lo que claramente deja ver en uno de sus considerandos, donde afirma:

"La ratio essendi del precepto, radica en fundamentos nada sólidos ni convincentes como son la comunidad patrimonial familiar o las consideraciones morales de no relajar los vínculos parentales más directos, tendiéndose, en la actualidad, a suprimir el precepto o, al menos, a recortar su ámbito de aplicación siempre supeditado a la voluntad del ofendido, habiéndose calificado, a veces, tal exoneración, con acritud, al afirmarse que sacrifica las realidades de la vida a una ficción tantas veces de palmaria falsedad, constituyendo una patente de corso para despojar de sus bienes a determinados parientes que, por muy cercanos que sean, sólo ellos son los llamados a excusar el despojo, no el Estado, siempre espléndido con los bienes ajenos". 
Naturalmente, sobre la base de estas consideraciones, no es extraño que el Tribunal cite una serie de sentencias donde se limita al máximo el efecto de la mentada excusa absolutoria, tanto en lo que toca a los parientes a que se refiere como a los delitos que abarcaría.

Y respecto a la STS 22.12.87 (A. 9822), aunque es cierto que en ella formalmente se pasa a llevar la voluntad de la víctima al castigar por lesiones un abuso deshonesto consistente en una violación anal no denunciada separadamente de la denuncia por violación propiamente tal, violación por la cual también se condena al incuplado, no es menos cierto que en el caso que se trata, parece obvio que materialmente la voluntad de la víctima era claramente perseguir todas las agresiones de que fue objeto, lo que se demostraría no sólo por haber permitido el examen médico en el sector anal, sino porque, de todos modos, al denunciar la violación ya incoa un proceso penal en el cual tiene que comparecer y hacer público los hechos que denuncia, entre los cuales se acredita no sólo la violación sino también el abuso deshonesto no denunciado separadamente.

\subsubsection{Aplicación de la ley en principio desplazada a los terceros partícipes}

Desde el punto de vista del concurso (aparente) de leyes, la participación delictiva no fue objeto de análisis dogmático explícito en España, sino hasta la aparición de la obra de Peñaranda (1991:153ss), donde se defiende la tesis asumida desde la obra de GEERDS en la dogmática alemana sobre el carácter personal que tendría el concurso (aparente) de leyes, esto es, la posibilidad de aplicar a los partícipes la ley en principio desplazada, cuando no pudiese aplicárseles la ley preferente y aplicable al autor principal.

La principal novedad del trabajo de PEÑARANDA (1991:38s, 190ss) sobre el carácter personal del concurso (aparente) de leyes, consiste en analizar en base al mismo situaciones que, aunque intuídas en la dogmática alemana, en ella no se estudiaban en profundidad, atendida la fuerte vinculación de este punto con la participación en los llamados actos posteriores copenados.

En efecto, con el propósito declarado de cuestionar la teoría de la llamada unidad del título de la imputación, se plantea PEÑARANDA la posibilidad de imputar sólo los tipos básicos -genéricos o subsidiarios- a los partícipes de un delito especial o principal caracterizado por la presencia de algún elemento típico de carácter personal, como en los llamados delitos especiales impropios, ${ }^{56}$ incluso objetivo, como en los casos que el partícipe desconoce ciertas circunstancias previas o no está de acuerdo ni

\footnotetext{
${ }^{56}$ Sobre esta categoría dogmática, cfr. QUINTERO (1974: passim).
} 
colabora en lo que se ha denominado "exceso del autor principal". En estos casos, afirma PEÑARANDA (1991:191), habiéndose realizado por el autor principal los requisitos típicos tanto de las figuras básicas o subsidiarias como de las especiales o principales, "para oponerse a calificar, por ejemplo, como partícipe de homicidio al extraño que induce a un hijo a dar muerte a su padre o auxilia a la madre a matar a su hijo recién nacido, es manifiestamente inidóneo el argumento de que aquel homicidio no habría tenido lugar [el subrayado es mío]", exigiendo se presenten otros argumentos más fuertes para no romper el título de la imputación y no castigar separadamente al partícipe por homicidio y al autor principal por parricidio.

Esta tesis de PEÑARANDA fue constestada rápidamente por GIMBERNAT (1992:passim), quien defiende la de que quien participa en un parricidio sólo puede ser partícipe de ese delito y no de un homicidio, delito que no se habría cometido-teoría de la unidad del título de la imputación que el mismo GIMBERNAT (1966) introdujera definitivamente en la dogmática española ${ }^{57}$.

Según GIMBERnAT (1992:836 nota 9, 837, 851), puesto que el concurso (aparente) de leyes no tendría un carácter personal, sino uno objetivo, el parricida no podría cometer a la vez un homicidio, en atención a que el parricidio no es una figura especial del homicidio sino un alliud, conclusión esta última que extrae del nuevo concepto de especialidad que introduce ${ }^{58}$.

De este modo, la cuestión acerca del delito que se comete "en realidad", si un parricidio, un homicidio, o ambos, queda resuelta ya desde el nivel de la tipicidad, en el cual, con el recurso al nuevo criterio de especialidad que introduce, GIMBERNAT reconstruye lás relaciones de las figuras en juego, descartando al especialidad, afirmando, en contra, la mutua exclusión de ambas. De allí que afirmar la imposibilidad de participar en un homicidio cuando el autor principal comete parricidio sea una conclusión necesaria en este esquema.

Sin embargo, esta respuesta no se refiere directamente al problema del resurgimiento de la ley desplazada respecto a los partícipes en caso de concurso (aparente) de leyes, pues de antemando se ha excluído tal concurso, al sostener que las normas en juego se encontraría relación de alliud-alliud. Queda, por tanto, abierta la pregunta acerca de si GIMBERNAT, en caso que se diese una relación de especialidad en el sentido que él postula, admitiría o no el castigo de los partícipes por la ley en

\footnotetext{
${ }^{51}$ V.gr., cfr. ESCRIVÁ (1983: passim) y el propio GIMBERNAT (1992:835 nota 4). Incluso la Jurisprudencia admite actualmente esta tesis, como puede verse en la STS 3.211 .93 (A. 8398), donde en un delito especial impropio se castiga al partícipe por el mismo título por el que se sanciona al autor principal, funcionario público.

${ }^{58}$ Cfr. Supra 8.2.1.
} 
principio desplazada, si no concurren en ellos los elementos especializantes que caracterizan al autor principal.

5. Conclusiones. Los efectos residuales y el resurgimiento de la ley en principio desplazada

\subsection{El problema conceptual}

Toda la evolución de la problemática de los efectos residuales y del resurgimiento de la ley en principio desplazada, tanto en la dogmática alemana como en la española, conlleva de fondo, la discusión acerca de qué clase de problemas enfrentamos cuando se habla del concurso aparente de leyes. En Chile, predominan quienes ven en él, desde la obra de A. Etcheberry: El concurso aparente de leyes penales, Santiago s/f, un simple "asunto de interpretación de las leyes penales" que "no existe concurso" ${ }^{60}$. Pero esta postura, como destaca el análisis de Peñaranda, $(1991: 45 s s)^{61}$, no parece permitir explicar adecuadamente la problemática central que aquí hemos expuesto: ¿ cómo es posible volver a aplicar una norma desplazada de antemano, ya desde el punto de vista de la interpretación penal? En cambio, si se entienden las reglas del concurso aparente de leyes como reglas propiamente concursales, que desplazan en sus efectos los de las normas concursales comunes (concurso real y concurso ideal), y que por tanto, no afectan la valoración jurídica del hecho (que se han realizado los supuestos de tales y cuales figuras penales), sino sólo las consecuencias de esa valoración a la hora de imponer una pena, la problemática desaparece y resta, solamente, establecer las condiciones y límites de este "resurgimiento" de la ley en principio desplazada. A estas ventajas hay que agregar las de su sencillez y la posibilidad que ofrece de discutir los argumentos acerca del valor y alcance de los criterios que, como metanormas o normas de segundo nivel, operan en la resolución de conflictos derivados de la concurrecia de disposiciones legales ${ }^{62}$.

\footnotetext{
${ }^{59}$ POLITOFF (1997:136). Antes, yo mismo en MATUS (1994:173).

${ }^{60}$ GARRIDO (1997 ॥:351).

${ }^{61}$ Así, expresamente ahora también MIR (1996:27/64 y 67).

${ }^{62}$ Sobre la necesidad de distinguir entre los criterios que determinan un conflicto y aquéllos que permiten solucionarlo, cfr. BOBBIO (1970:95-118).
} 
5.2. Los efectos residuales: aplicación de la ley en principio desplazada en la determinación de la pena

Salvo en los casos de especialidad en que prefiere un delito privilegiado, no parece prohibido por la ley, ni incompatible con la preferencia dada a una de las normas concurrentes, estimar las propiedades jurídico-penalmente relevantes de la ley desplazada y que no se encuentran comprendidas en la preferente, como circunstancias del hecho posibles de considerar en la concreta determinación de la pena, a través de las reglas previstas en los arts. 65ss (si tales propiedades pueden constituir circunstancias agravantes no comprendidas en el delito preferente), y particularmente en la del art. 69, cuando tales propiedades no puedan apreciarse aisladamente en la configuración de circunstancias agravantes.

\subsection{El resurgimiento de la ley desplazada: su aplicación en casos en que no es aplicable} la ley principal

Al contrario de lo que sucede con los efectos residuales de la ley en principio desplazada, no surgen problemas dogmáticos o conceptuales a la hora de admitir en general, pero no sin excepciones, el resurgimiento de la ley en principio desplazada, esto es, la aplicación de ésta cuando no se presentan en los hechos todos los requisitos de punibilidad o de procesabilidad de la ley en principio preferente, así como cuando el castigo por ésta se encuentra impedido por existir un error en el agente sobre un elemento del delito en principio preferente, por no serle aplicable al partícipe una característica especial atribuible sólo al autor principal, o por haber sido éste indultado, - que con posterioridad el delito preferente sea amnistiado o prescriba, o la ley preferente sea derogada, etc.. Así sucede paradigmáticamente con el caso de la tentativa calificada desistida (Politoff, Actos preparatorios..., 1999, 238).

Sin embargo, el resurgimiento no tiene lugar cuando se trata de hacer resurgir una ley desplazada más grave que la en principio preferente (una norma general sobre una privilegiada, por ejemplo), casos en los cuales el privilegio establecido por la ley no se tomaría nunca en cuenta. Tampoco lo tendrá cuando el delito en principio preferente no sea aplicable por faltar alguna condición de procesabilidad o perseguibilidad del mismo, si ese obstáculo procesal es la denuncia o querella del ofendido por el delito, pues en tales circunstancias no puede hacerse resurgir la figura desplazada sin pasar a llevar con ello la voluntad legislativa de entregar a la víctima del delito la decisión de si participará o no en un proceso penal. Lo mismo ocurre cuando dicho requisito es una declaración de autoridad (como la querella del S.I.I. o la declaración de quiebra) que debe preceder a la persecución criminal, pues entonces no tendría sentido tal declaración de autoridad. 


\subsection{El resurgimiento de la ley en principio desplazada y su aplicación a los terceros} partícipes en el delito

Se trata de un caso especial de resurgimiento que responde a la pregunta acerca de qué pasa cuando en un caso de concurso aparente de leyes no concurre en uno de los partícipes la circunstancia especializante o la que determina la subsidiariedad, consunción o alternatividad. En estos casos, como entiende nuestra doctrina prácticamente unánime al resolver el problema de la participación en el delito de parricidio (Cf. Politoff /Bustos/Grisolía, 127s), respecto del partícipe en quien no concurren las circunstancias personales que determinan la preferencia de un precepto en perjuicio de otro, tal preferencia no se produce y resurge para él la ley en principio desplazada. Los fundamentos legales de esta solución se encuentran en los arts. 17, 61, $64,72,269$ y 489, que hace reposar la responsabilidad penal de cada partícipe por separado, y demuestran que existe en nuestra legislación un principio general, según el cual las causas de exclusión de la pena que se derivan de una característica personal no son extensibles a los partícipes en quienes no concurre dicha característica.

\section{BIBLIOGRAFÍA CITADA}

Bacigalupo Zapater, Enrique: (1990) Principios de Derecho penal, PG, Madrid 1990.

BAUMANN, Jürgen: 1968) Strafrecht AT, 5. neubearbeitete Aufl., Bielefeld 1968.

BAUMANn, Jürgen/Weber Ulrich: (1985) Strafrecht AT. Ein Lehrbuch, 9. Aufl., Bielefeld 1985.

BAUMGARTEN, Arthur: (1909) Die Lehre von der Idealkonkurrenz und Gesetzeskonkurrenz, Breslau 1909.

BERG, Hans: (1953) Der Aufbau des strafrechtlichen Gutachtens, en JZ 1953, 26.

BINDING, Karl: (1885) Handbuch des Strafrechts Bd. I, Leipzig 1885.

BLEl, Hermann: (1983) Strafrecht I AT. Ein Studienbuch. 18. Aufl. des von E. Mezger begründeten Werkes, München 1983.

BoBBIO, Norberto: (1970) Sui criteri per risolvere le antinomie, en del mismo: Estudi per una Teoria Generale del Diritto, Torino 1970, 95.

BoCKelmanN, Paul: (1941) Zur Lehre von der Idealkonkurrenz, en ZAkDR 1941, 293. (1953) Comentario al fallo OLG Hamm 4.11.1952, en JZ 1953, 233. (1960) Zur Konkurrenz der Vermögensdelikte. Bemerkungen zum Beschluß des Großen Strafsenats BGHSt 14, 38, en JZ 1960,621 . 
BRINGEWAT, Peter: (1987) Die Bildung der Gesemtstrafe, Berlin/New York 1987.

BRUNS, Hans-Jürgen (1974) Strafzumessungsrecht (Gesamtdarstellung), 2. neubearbeitete Aufl., Köln 1974. (1985) Das Recht der Strafzumessung, 2. Aufl., Köln 1985.

Bustos Ramírez, Juan/HORMAZÁBAL Malarée, Hernán: (1994) Manual de derecho penal, $P G, 4^{2}$ ed., Barcelona 1994.

CID Moline, José: (1994) Notas sobre las definiciones dogmáticas de concurso de delitos, en ADPCP 1994, 29.

Conde-Pumpido Ferreiro, Cándido: (1990) Comentario al Art. 68 del Código Penal, en López BARJA, Jacobo/Rodriguez Ramos, Luis: Código penal comentado, Madrid 1990, 199.

Córooba Roda, Juan: (1972) Comentario a los artículos 68 a 71 Cp 1944, en el mismo/Rodríguez Mourullo, G./Toro Marzal, A. del/Casabó Ruiz, J.: Comentarios al Código penal t. II, Barcelona 1972.

Cramer, Peter: (1970) Das Strafensystem des StGB nach den 1. April 1970, en JurA 1970, 183

CUELLo CONTRERAS, Joaquín: (1978) La frontera entre el concurso de leyes y el concurso ideal de delitos: El delito sui generis, en ADPCP 1978, 35. (1979) La frontera entre el concurso de leyes y el concurso ideal de delitos: La función de la normativa concursal (I) y (II), en ADPCP 1979,45 y 451 .

CUERDA Riezu, Antonio: (1992) Concurso de delitos y determinación de la pena, Madrid 1992.

DREHER, Eduard: (1964) Comentario al fallo OLG Braunschweig de 28.6.1963, en MDR $1964,167$.

DREHER, Eduard/TRÖNDLE, Herbert: (1993) Strafgesetzbuch und Nebengesetze, 46., neubearbeitete Auflage des von Otto vgyhdfbgv Schwarz begründeten Werkes, München 1993.

DünNEBIER: (1954) Die Subsidiaritätsklausel, en GA 1954, 271.

ESCRIVÁ Gregori, José M: (1983)La participación del extraneus en el parricidio y del ((intraneus) en el homicidio, en Estudios jurídicos en honor del Profesor Octavio Pérez-Vitoria, $t$. I., Barcelona 1983.

Frank, Reinhard: (1931) Das Strafgesetzbuch für das Deutsche Reich, 18. Aufl., Tübingen 1931. 
García Albero, Ramón: (1995) Non Bis in Idem Material y Concurso de Leyes Penales, Barcelona 1995.

GEERDS, Friederich: (1961) Zur Lehre von der Konkurrenz im Strafrecht, Hamburg 1961. (1981) Comentario al fallo OLG Celle de 11.3.1980, en JR 1981, 35.

GEPPERT, Klaus: (1982) Grundzüge der Konkurrenzlehre ( $\$ \S 52$ bis 55 StGB), en Jura 1982,358 y 418.

GERLAND, Heinrich: (1932) Deutsches Reichsstrafrechts, 2. Aufl., Berlin/Leipzig 1932.

Gimbernat Ordeig, Enrique: (1966) Autor y cómplice en Derecho penal, Madrid 1966. (1992) Concurso de leyes, error y participación en el delito (A propósito del libro del mismo título del profesor Enrique Peñaranda), en ADPCP 1992, 833.

GonzÁlez Pulido, Abelardo: (1989) El efecto de cierre en el concurso aparente de normas penales $y$ en el concurso ideal de delitos: su trascendencia respecto de los delitos calificados por el resultado (Comentario a la STS de 6 de abril de 1989), en PJ 14 (1989), 191.

HÄNDEL, Konrad: (1964) Comentario al fallo BGH de 26.5.1964, en NJW 1964, 1733.

HARTUNG, Fritz: (1939) Die Strafe beiTateinheit, en DR 1939, 1484.(1954) Subsidiarietät der Verkehrsübertretungen?, en NJW 1954, 587.

HeInEmAnN, Hugo: (1893) Die lehre von der Idealkonkurrenz, Berlin 1893.

HIPPEL, Robert v. (1930) Deutshes Strafrecht in 2 Bänden, Band 2.: Das Verbrechen, allgemeine Lehren, Berlin 1930.

HIRSCHBERG, Rudolf: (1934) Zur Lehre von der Gesetzeskonkurrenz, en ZStW 53 (1934), 34.

HOEGEL: (1916) Akzessorische Natur der Teilnahme, mittelbare Täterschaft und Eventualvorsatz, en ZStW 37 (1916), 826.

HRUSCHKA, Joachim: (1967) Konkurrenzfragen bie den sog. erfolgsqualifizierten Delikten, en GA 1967, 42.

JAGUSCH, Heinrich: (1957) Vorbemerkungen zur $\S \S 73$ ff. StGB, en Leipziger Kommentar, 8. Aufl., Berlin 1957, 597.

JESCHECK, Hans-Heinrich: (1955) Die Konkurrenz, en ZStW 67 (1955), 529. (1988) Lehrbuch des Strafrechts AT, 4. Aufl., Berlin 1988. 
KOCH, Hans-Jörg; (1960) Sondergesetz, Subsidiaritätsklausel und Sicherungsmassregel, en GA 1960, 1.

KÖHLER, August: (1900) Die Grenzlinien zwischen Idealkonkurrenz und Gesetzeskonkurrenz, München 1900.

KoHLmann, Günter:(1964) Schließt die Verjährung der Vortat auch die Bestrafung wegen der Nachtat, ous?, en JZ 1964, 492.

KRAUB, Detlef: (1965) Zum Begriff der straflosen Nachtat, en GA 1965, 173

KüHL, Kristian: (1978) Das leidige Thema der Konkurrenzen, en JA 1978, 475. (1994) Strafrecht AT, München 1994.

LACKNER, Karl: (1993) Strafgestzbuch mit Erläuterungen, 20, neubearbeitete Auflage des von Dr. Eduard Dreher und Dr. Hermann Maassen begründeten Werkes, München 1993.

LISzT, Franz von: (1884) Lerhbuch des deutschen Strafrechts, 2. Aufl., Berlin/Leipzig 1884 .

LISZT, Franz v./SCHMIDT, Eberhard: (1932) Lehrbuch des deutschen Strafrechts, 26. Aufl. neubearbeitete von Schmidt, Eberhard, Berlin/Leipzig 1932.

LóPEZ BARJA de Quiroga, Jacobo: (1991) Teoría de la pena, Madrid 1991.

Luzón CUESTA, José María: (1994) Compendio de Derecho penal, PG, 6ta. ed., Madrid 1994.

MAATZ, Kurt: (1995) Kann ein (nur) versuchtes schwereres Delikt den Tatbestand ein vollendeten milderen Delikts verdrängen?, en NStZ 1995, 211.

MAQUedA Abreu, María Luisa: (1983) El error sobre las circunstancias. Consideraciones en torno al artículo 6ºis a), del Código Penal, en CPC 21 (1983), 699.

MARtínez GonzÁlez, Mª Isabel: (1988) El delito de robo con homicidio, Barcelona 1988.

MAURACH, Reinhart: (1954a) Deutsches Strafrecht, AT, Karlsruhe 1954.

MAYER, Hellmuth: (1953) Strafrecht AT, Stuttgart/Köln 1953.

MAYER, Max Ernest: (1915) Der allgemaine Teil des deutschen Strafrechts. Lehrbuch, Heidelberg 1915.

Merkel, Adolph: (1877) Die Ideale Konkurrenz, en HoltzendorfF, Franz v. (Hrsg.): Handbuch des deutschen Straftrechts (Ergänzungen zum deutschen Strafrecht) Bd. IV, Berlin 1877, 225.(1889) Lehrbuch des deutschen Strafrechts, Stuttgart 1889. 
MezGer, Edmund: (1941) Comentario al fallo RG 73, 148, en DR 1941, 921 (1949) Strafrecht. Ein Lerhbuch, 3. Aufl., Berlin/München 1949.

MIR Puig, Santiago: (1981) Adiciones de Derecho español, en JESCHECK, Hans-Heinrich: Tratado de Derecho penal PG, $3^{2}$ ed. Traducción de Mir Puig, Santiago y Muñoz Conde, Francisco, 2 tomos, Barcelona 1981. (1990) Derecho penal, PG, $3^{32}$ ed., Barcelona 1990. (1996) Derecho penal, PG, 4ª ed., Barcelona 1996.

MITSCH, Wolfang: (1993) Gesetzeseinheit im Strafrecht, en JuS 1993, 471.

Morillas Cueva, Lorenzo: (1992b) Conducción temeraria con consciente desprecio a la vida de los demás (340 bis d)), en CLP XIV, 1ำ (1992), 145.

Muñoz Conde, Francisco/García ARÁn, Mercedes: (1993) Derecho penal, PG, Valencia 1993.

NAGLER, Johanes: (1944) Vorbemerkungen zur 1. Teil, 5. Abschnitt des Strafgesetzbuchs, en Leipziger Kommentar, 6. Aufl., Berlin 1944, 548.

NIESE, Werner: (1953) Die Rechtsprechung des Bundesgerichtshofs in Strafsachen, en JZ 1953,73. (1954) Empfiiehlt sich die Einführung einer einheitlichen Strafe auch im Falle der Realkonkurrenz, en Materialien zur Strafrechtsreform Bd. I, Bonn 1954, 55.

PeÑARANDA Ramos, Enrique: (1991) Concurso de leyes, error y participación en el delito, Madrid 1991.

PETERS, Karl: (1944) Einheitsstrafe bei Verbrechensmehrheit, en Festschrift für Eduard Kohlrausch, Berlin 1944, 199.

PREISENDANZ, Holger: (1978) Strafgesetzbuch: Lehrkommentar mit Erläuterungen und Beispilen, 30. Aufl, Berlin 1978.

PUIG PEÑA, Federico: (1952) Concurso de leyes penales, en NEJ IV (1952), 843. (1955) Colisión de normas penales, concurso aparente de leyes punitivas, Barcelona 1955.

QUINTERO Olivares, Gonzalo: (1974) Los delitos especiales y la teoría de la participación en el Derecho penal español, Barcelona 1974. (1989) Derecho penal, PG, $2^{a}$ ed. con la colaboración de Morales Prats, Fermín y Prats Canut, J. Miguel, Madrid 1989.

Quintero Olivares, Gonzalo/Morales Prats, Fermín/Prats Canut, J. Miguel: (1996) Curso de Derecho penal, PG, Barcelona 1996.

Rodríguez Mourullo, Gonzalo: (1978) Derecho penal, PG, Madrid 1978 
SAMSON, Erich: (1987) Comentarios previos al § 52 StGB y comentarios al § 52 StGB, en Systematischer Kommentar zur Strafgesetzbuch, 5. Aufl, Neuwield/Kriftel 1987.

SÁnCHEZ TOMÁs, José M.: (1993) Relaciones normativas de exclusión y de especialidad: la problemática del error sobre elementos que agravan la pena a través del ejemplo del error sobre la edad de doce años (violación-estupro), en ADPCP 1993, 679.

SANZ Morán, Ángel: (1986) El concurso de delitos, aspectos de técnica legislativa, Valladolid 1986.

SAUER, Wilhelm: (1955) Allgemaine Strafrechtslehre, 3. Aufl., Berlin 1955.

SAUERMANn, Karl: (1927) Der Versuch als delictum sui generis, en Strafrechtliche Abhandlungen, Heft 227. Breslau 1927.

SCHLOSKY: (1942) Über Tateinheit und fortgesetztes Verbrechen, en ZStW 61 (1942), 245.

SCHMIDHÄUSER, Eberhard: (1975) Strafrecht AT. Lehrbuch, 2. Aufl., Tübingen 1975.

SCHNEIDER, Egon: (1953) Zur Gesetzeskonkurrenz im strafrechtlichen Gutachten, en JZ 1953,660 .

SCHÖNKE, Adolf: (1951) Strafgesetzbuch Kommentar, 5. neubearbeitete Aufl., München/Berlin 1951.

SCHÖNKE, Adolf/SCHRÖDER, Horst: (1954) Strafgesetzbuch Kommentar, 7. Aufl., München/Berlin 1954.

SCHONKE, Adolf/SCHRÖDER, Horst/STREE, Walter: (1991) Comentarios previos a los $\S \S$ 38ss. y 52ss., y comentarios al § 73 St GB, en SCHÖNKE, Adolf/SCHRÖDER, Horst: Strafgestzbuch Kommentar, 24. Aufl.. München 1991

SCHRÖDER, Horst: (1965) Comentario al fallo BGH 20, 235, de 7.7.1965, en JZ 1965, 729.

SCHÜnEmAnn, Bernd: (1968) Die Stellung der Unterschlagungstatbestände im System der-Vermögensdelikte BGHSt 14, 38, en Jus 1968, 114.

SCHWARZ: (1939) Die Straffestsetzung bei der Tateinheit, en ZAkDR 1939, 672.

SEIR, Jürgen: (1983) Die Gesetzeseinheit und ihre Rechtsfolgen, en Jura 1983, 225.

SIEGERT: (1933) Beihilfe zur straflosen Nachtat, en GA 1933, 98. 
STRATENWERTH, Günther: (1981) Strafrecht AT I: die Straftat, 3. neubearbeitete Aufl., Köln/München 1981.

SUÁREZ MONTES, Rodrigo Fabio: (1983) Observaciones a la penalidad del robo con homicidio en la reforma de 1983, en La Ley 1983-4, 1286.

THOMSEN, Andreas: (1906) Das deutsche Strafrecht AT, Berlin 1906.

VOGLER, Theo: (1979) Funktion und Grenzen der Gesetzeseinheit, en Festschrift für Paul Bockelmann, München 1979, 715. (1985) Comentarios previos y posteriores al § 52 StGB, en Leipziger Kommentar, 10. Aufl, Berlin 1985.

VoLL, Gustav: (1958) Konkurrenzen, en Niederschriften über die Sitzungen der Großen Strafrechtskommission 2. Bd, Anhang Nr. 60, Bonn 1958, 165.

WACHENFELD, Friedrich: (1893) Theorie der Verbrechenkonkurrenz, Berlin 1893.

WARDA, Günter: (1964) Grundfragen der strafrechtlichen Konkurrenzlehre, en JuS 1964, 81.

Welzel, Hans: (1969) Das deutsche Strafrecht, 11. Aufl., Berlin 1969.

WESSELS, Johannes: (1993) Strafrecht AT, 23. Aufl, Heidelberg 1993.

ZIPF, Heinz: (1969) Die Strafmaßrevision, München 1969.

Zugaldía Espinar, José Miguel: (1993) Fundamentos de derecho penal, $3^{2}$ ed., Valencia 1993. 